Journal of Experimental and Clinical Medicine https://dergipark.org.tr/omujecm

Review Article

J Exp Clin Med

2021; 38(4): 649-668

doi: $10.52142 /$ omujecm.38.4.44

\title{
Epidemiology, virology, clinical features, diagnosis, and treatment of SARS-CoV-2 infection
}

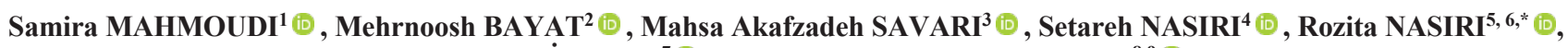 \\ Abolfazl JAFARİ-SALES ${ }^{7}$ (i) , Hossein BANNAZADEH-BAGHI ${ }^{8,9}$ [i] \\ ${ }^{1}$ Department of Microbial Biotechnology, School of Biological Sciences, Islamic Azad University North Tehran Branch, Tehran, Iran \\ ${ }^{2}$ Department of Microbiology, School of Paramedicine, Islamic Azad University Boroujerd Branch, Boroujerd, Iran \\ ${ }^{3}$ Isfahan Clinical Toxicology Research Center, Isfahan University of Medical Sciences, Isfahan, Iran \\ ${ }^{4}$ Department of physical education and sport sciences, Isfahan (Khorasgan) Branch, Islamic Azad University, Isfahan, Iran \\ ${ }^{5}$ Iran National Elite Foundation, Tehran, Iran \\ ${ }^{6}$ Department of Cell and Molecular Biology and Microbiology, Faculty of Biological Science and Technology, University of Isfahan, Isfahan, Iran \\ ${ }^{7}$ Department of Microbiology School of Basic Sciences, Kazerun Branch, Islamic Azad University, Kazerun, Iran \\ ${ }^{8}$ Infectious and Tropical Diseases Research Center, Tabriz University of Medical Sciences, Tabriz, Iran \\ ${ }^{9}$ Immunology Research Center, Tabriz University of Medical Sciences, Tabriz, Iran
}

\begin{abstract}
Received: 16.02 .2021
Accepted/Published Online: 24.02 .2021

-

Final Version: 30.08.2021

\section{Abstract}

Since December 2019, the severe acute respiratory syndrome coronavirus 2 (SARS-CoV-2) has emerged and spread quickly worldwide. The disease is generally mild in adult people but in any with comorbidities may proceed to acute respiratory distress syndrome (ARDS), pneumonia, and multi-organ dysfunction. By performing molecular tests on respiratory secretions can diagnose the virus. Elevated C-reactive protein (CRP) and normal/low white cell counts are common laboratory diagnoses of COVID-19 while the tomographic chest scan is usually irregular for many infected people. Some patients progress to respiratory failure, pneumonia, and finally death by the end of the first week of illness because of the sharp rise in inflammatory cytokines such as IL7, IL2, GCSF, IL10, MIP1A, MCP1, IP10, and TNF $\alpha$. Various approaches to the COVID19 are being performed by scientists. Use of chemical medical drugs that are effective for other viral infections. Among them, remdesivir was approved by FDA on 1th May 2020 because of its impact to treat patients. Also, several studies have revealed that many Chinese herbal remedies have a remarkable impact on the healing process when simultaneously were used along with pharmacological drugs. In the meantime, many efforts have been made to produce an effective vaccine, and so far, the Ad5-vectored COVID-19 vaccine has been successful and has entered phase 2 in the human trial. The current review focus on epidemiology, virology, clinical features, diagnosis, and available treatment of coronavirus that might assist researchers and clinicians in establishing action options for timely against this infection.
\end{abstract}

Keywords: coronavirus, COVID-19, SARS-CoV-2, severe acute respiratory syndrome, treatment

\section{Introduction}

Coronaviridae is a family of positive-single-stranded RNA viruses that its length is in the range 26-32 kilobases and has a 5 cap structure and 3 polyadenylation tract (1). On the surface of these viruses, there is a crown-like protein and this is the reason that they were named Coronaviruses. As can be seen in Fig.1, the family Coronaviridae is classified into two subfamilies: Orthocoronavirinae and Letovirinae. The subfamily Orthocoronavirinae contains four genera, including Gammacoronavirus, Alphacoronavirus, Betacoronavirus, and Deltacoronavirus (2). The betacoronavirus genus is divided into five sub-genres of ancestors (3). Genomic studies have shown that the gene sources of alphaCoVs and betaCoVs are from rodents and bats, further, deltaCoVs, and gammaCoVs are from avian species (4). Among the species of coronaviruses, seven of them are related to humans, including HCoV-OC43, MERS-CoV, HCoV-HKU1, and SARS-CoV, which are from betacoronavirus genus, plus, $\mathrm{HCoV}-229 \mathrm{E}$ and
HCoV-NL63 that are from Alphacoronavirus genus (5). Genome sequencing of viruses isolated from patients with SARS-Cov-2 has shown that most of the sequences are similar. The SARS-Cov-2 genome sequence is about $96.2 \%$ similar to the Bat SARS-like CoVs, $79.5 \%$ similar to the SARS-CoV, and 50\% similar to the MERS-CoV. Bat SARSlike CoVs include bat-SL-CoVZXC21 and bat-SL-CoVZC45 (6). Because of these similarities, the novel coronavirus was called SARS-CoV-2. The length of SARS-CoV-2 RNA is exactly 29891 nucleotides that encode 9860 amino acids (4). The SARS-CoV-2 genome is generally similar to Bat-SARS$\mathrm{CoV}$, but the SARS-CoV-2 proteins are similar to SARS-CoV (5). One study discovered that the SARS-CoV-2 genome can mutate in different patients, but the mutation was much less than the changing of H7N9 avian influenza (7). The frame of most coronaviruses is the same size, except a floating part (610) of open reading frames (ORFs). There are transcription 
regulatory sequences between the ORF, which are templates for the production of sub-genomic mRNAs. Sixteen nonstructural proteins are encoded by the first part of the ORF and accessory proteins are encoded by the rest of the ORF (8). Nucleocapsid protein $(\mathrm{N})$, small envelope protein $(\mathrm{E})$, spike glycoprotein (S), and matrix protein (M) are four essential structural proteins. These proteins interact with the human innate immune response (9).

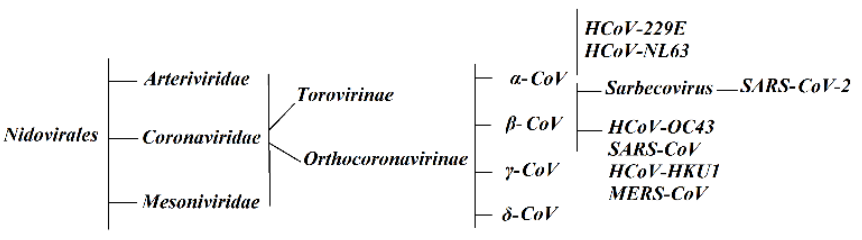

Fig. 1. Human Coronavirus classification

These viruses in animals and humans lead to enteric, intestinal, and respiratory diseases, and in some cases to diseases of the nervous system (10). Most kinds of human coronaviruses have been associated with diarrhea, colds, and in some cases, occurring multiple sclerosis (11). Coronaviruses were first discovered in the mid-1960s (12) and they were not very popular before 2003 because they just had been causing nearly 10 to 15 percent of colds, and rarely caused serious lower respiratory region disease until Severe Acute Respiratory Syndrome was distinguished in China. SARS-CoV could have arisen as a mutant of a human coronavirus (13). In 2012, another type of coronavirus called Middle East Respiratory Syndrome (MERS) was first diagnosed in the Middle East. This strain was another mutant type of coronavirus, which was isolated from a person with flu-like symptoms (14). Finally, a novel coronavirus has appeared in early December 2019 (15). The coronavirus disease 2019 is called abbreviation COVID-19 and leads to an acute respiratory disease (16).

The first report of acute respiratory infection was revealed on December 12, 2019, in the seafood market in Wuhan, China. It is supposed that the animal-to-human transmission was the first mechanism to transmit the SARS-CoV-2. Yet, some of the following cases did not deal with this market at all, so it is obvious that human-to-human delivery has occurred. Patients with symptoms are serious carriers of the virus (17). COVID-19 is an acute infectious disease that is first transmitted through direct contact with the SARS-CoV-2 or respiratory droplets of people infected with the virus (18) or exposed to high aerosol concentrations in restricted spaces (4). On January 7, 2020, Chinese scientists isolated the virus from infected people and sequenced it. Since the phylogenetic structure of SARS-Cov-2 has a high correlation to Bat SARSlike CoVs (19), it has been suggested that an animal has played the important role of intermediate host to transfer the virus in the market $(20,21)$. There is a unique peptide (PRRA) in batCOV and human SARS-CoV-2 virus but pangolins do not have this RRAR motif, thus, SARS-CoV-2 did not come directly from pangolins (22). Fig. 2 represents the schematic image of SARS-CoV-2 structure and transmission into human.
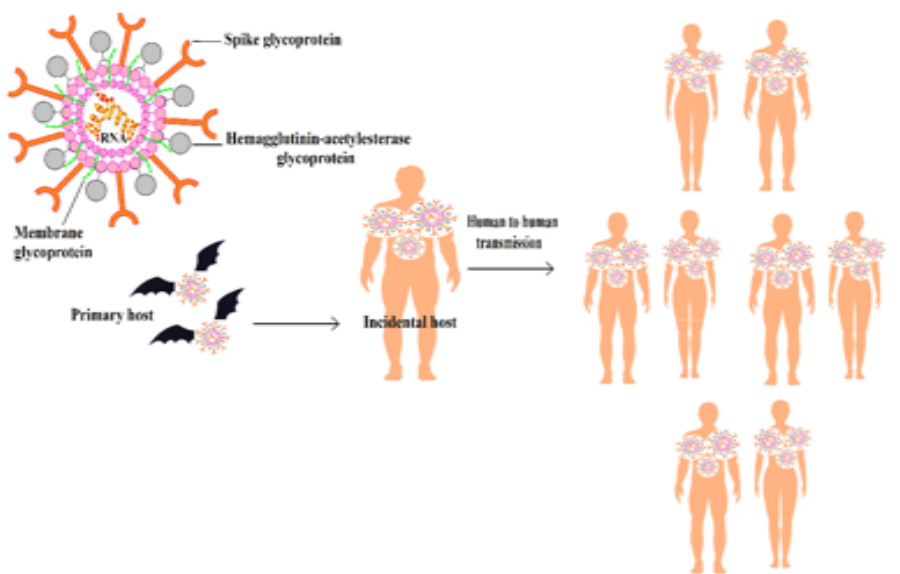

Fig. 2. Schematic representation of SARS-CoV-2 transmission into human

However, the emergency needs to control infected people with the virus has not yet allowed for a more detailed survey about the intermediate host. On January 12, 2020, the virus was named 2019- novel coronavirus, and subsequently on February 11, 2020, the virus and the disease it caused were called SARS-CoV-2 and coronavirus disease 2019 (COVID19). Now, the transmission of SARS-CoV-2 occurs mainly between human-to-human, while nosocomial transmission occurs for SARS-CoV and MERS-CoV $(23,24)$. The World Health Organization (WHO) stated the SARS-CoV-2 as a new epidemic on February 28, 2020. Finally, the novel epidemic intensified about every seven days (4) until, $11^{\text {th }}$ March, COVID-19 was officially announced a pandemic by the WHO and as of August 2020, SARS-CoV-2 has infected nearly $23.000,000$ people and caused more than 790,000 deaths (https://www.worldometers.info/coronavirus/). COVID- 19 is a late and long illness thus, People who are infected these days will start showing patient symptoms soon. A study presented that if the pandemic is left unchecked, for every possible critical-care bed, there will be nearly 15 COVID-19 patients by the end of June. The first possibility is that every country head to simultaneously make the virus to heel, as the SARS in 2003. The second possibility is that the virus passes through the population around the world and finally leaves people who have strong immune systems (25).

\section{Clinical characteristics, symptoms and laboratory diagnostic}

The incubation time of COVID-19 is on average 3-14 days, during this time the person would be disease carrier. The first detection of the virus in China was performed by electron microscopy using a morphological examination of SARSCoV-2 (26). The risk of this disease is higher for the elderly or people with immunodeficiency. Men are also more likely to get it with $56 \%$ than women with 41.9 to $45.7 \%$ (27). In a study by Zhang et al, it is reported that the virus is presented 
in the blood and fecal swabs of the infected person (28). Symptoms in patients include cough and fever, and most people indicate mild flu-like symptoms. In people with this severe disease, symptoms of shortness of breath, failure of some organs, and even death are observed (29).

Older people show more severe symptoms than others when they become infected, also, contrary to the first impression, many children can get the disease (30). The frequent clinical symptoms include headache, sore throat, shortness of breath, sputum production, fatigue, cough, and fever with about $13.6 \%, 13.9 \%, 18.6 \%, 33.4 \%, 38.1 \%$, $67.8 \%$, and $88.7 \%$, respectively (31). Some patients express that in addition to mentioned symptoms, they have gastrointestinal symptoms such as vomiting and diarrhea with nearly $5.0 \%$ and $3.8 \%$. Of all the symptoms, fever and cough are the most common (29). In many patients, the number of white blood cells and lymphocytopenia is reduced (32), but severe symptoms of the respiratory syndrome is decreased. Plus, creatinine levels, blood urea, neutrophil levels, and inflammatory factors increase in these people (29). Generally, the procalcitonin value is normal in most patients. CT imaging reveals pneumonia. There are a bilateral patchy shadowing and ground-glass opacity on the chest. Also, a peripheral lung distribution and a rounded morphology can be seen (33). The disease is divided into three groups based on the symptoms; about $85 \%$ of infected people undergo mild to modest infection and nearly $10 \%$ have vigorous infections and 5\% experience critical cases half of which die (34).

Currently, the main method for diagnosis is real-time PCR, which makes a double-stranded DNA from the viral RNA. This method is performed on samples taken from a throat swab, nasal, and other respiratory tract samplings (35) that should be immediately stored at $4^{\circ} \mathrm{C}$ after collection. If the result of RT-PCR from blood or respiratory samples would be positive, it means that the person has been infected (30). The following are disease division based on the symptoms:

1. Mild Illness; People with the disease show mild symptoms of the respiratory virus, including dry cough, mild fever, muscle pain, etc. Shortness of breath does not exist in these people at all.

2. Modest Pneumonia; There are no signs of severe pneumonia, but the shortness of breath and cough is obvious.

3. Severe Pneumonia; People with acute pneumonia have much more severe symptoms, such as shortness of breath and tachypnea, so they need artificial oxygen. But the degree of fever varies from person to person.

4. Acute Respiratory Distress Syndrome (ARDS); This syndrome leads to severe respiratory failure. The occurrence of hypoxia is one of the obvious symptoms. ARDS is divided into three categories based on the amount of hypoxia; mild ARDS, moderate ARDS, and severe ARDS.

Sepsis, The dysfunction of vital human organs due to infection is called sepsis (36). Very serious and dangerous symptoms can be seen in a person with sepsis. These symptoms include tachycardia, renal impairment, and severe hypoxemia and dyspnea (4).

\section{Pathogenesis and mechanism of action}

The effects of SARS-CoV-2 infection varies in different people and the foundation of differences is not still apparent. By sequencing the SARS-CoV-2, it was identified that there are several similarities between SARS-CoV-2 and SARS$\mathrm{CoV}-1$, for example, the 3D structure of $\mathrm{S}$ protein on the viral surface and the kind of receptors that it has an affinity to it (37). Cellular responses to the SARS-CoV-1 are different. The cellular tropism might be related to the differential expression level of membrane receptors for the virus. The most obvious receptor that the SARS-CoV uses to enter is Angiotensin-converting enzyme 2 (ACE2). Through COVID19 infection, the $\mathrm{S}$ protein of the virus is split into subunits; $\mathrm{S} 1$ and S2. The receptor-binding domain (RBD) is the site that binds to host cell receptors. RBD is situated in the $\mathrm{S} 1$ subunit. Membrane fusion is performed by S2 (38). This receptor prevents lung fibrosis by reducing angiotensin one and two during some processes. But when the receptor is involved by the virus, lung damage occurs (39). Fig. 3 shows the schematic representation of the SARS-CoV-2 replication in human respiratory system.

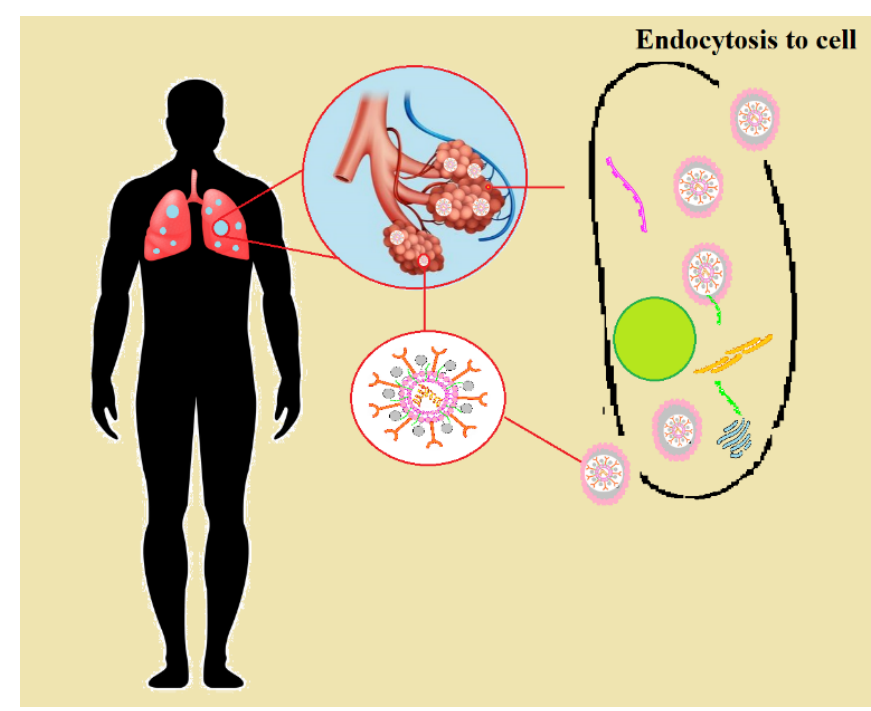

Fig. 3. Schematic representation of the SARS-CoV-2 replication in human respiratory system

The virus uses another receptor called transmembrane protease serine 2 (TMPRSS2) while interacting with the ACE2 receiver. TMPRSS2 is essential for priming and the viral spread of SARS-CoV-2. In other words, it was shown that in vitro studies, TMPRSS2 activates the S protein, which in turn, induces virus-cell membrane fusion at the host cell surface. Although this role of TMPRSS2 during coronavirus infection in vivo has still some unclear aspects, we think it 
may be the same in COVID-19 infection (40). It has been shown that the greatest damage to lung tissue in all severe cases is caused by severe inflammation, not the direct effect of the SARS-CoV-2 itself (41). Excessive immune response is responsible for severe pneumonia and respiratory failure. In some cases, immune systems are not able to stop their inflammatory response and lead immune cells into the lungs known as the cytokine storm (42), elevating IL-6, lymphopenia, ferritin, D-dimers, and raised neutrophil to lymphocyte ratio $(42,43)$. It is worth noting that this pathogenic outcome is similar to SARS CoV-1. In patients with severe respiratory syndrome three stages occur; a) escape from the immune system and suppress IFN, which causes the virus to multiply easily, b) cytokine storm, and c) manifestation of severe symptoms due to the unregulated inflammation. In patients with the mild disease experience a robust adaptive immune response in the first seven days, then, the titers of helper T cells, activated CD8 T, and CD4 T cells are enhanced (44) ACE2 is a well-known receptor of SARS$\mathrm{CoV}$ involves in pathogenesis (45). Using the same receptor by the SARS-CoV-2 for infecting the host has been approved by earlier research (34). As soon as the virus attaches to the cell, the viral +ssRNA enters to the human cell cytoplasm and is translated, then, two proteins (named pplab and ppla) are encoded. These non-structural protein construct a replicationtranscription complex (RTC) in double-membrane vesicles (46). The role of RTC is making sub-genomic RNAs that encode structural viral proteins (47). Another receptor that is involved in entry SARS-CoV-2 is TMPRSS2 (48). There are several possible causes for the virus to spread so quickly, such as: happening right at the height of the crowd at the Chinese Spring Festival, Lack of accurate knowledge of virus mechanisms to enter host cells (35).

The following biochemical events related to the viral replication cycle occur as soon as the viral RNA genome is released into the cells. RNA-dependent RNA polymerase is in charge of starting biosynthetic events of SARS-CoV-2 replication in the cytoplasm of infected cells. Coronavirus replication requires to continue protein synthesis from the very start of viral infections. Transcription is done through a replication-transcription complex (RCT) that is organized into two-membrane vesicles by synthesizing the sequence of subgenomic RNAs (sgRNAs). ORFs act as templates for generating subgenomic mRNAs. Atypical CoV genomes can have at least six ORFs (ORF3a, ORF7a, orflab, ORF8, ORF6, and ORF10). Amongst these, a frame change between ORF1a and ORF1b makes the output of ppla and pplab polypeptides, which are processed by encrypted proteases such as chymotrypsin (3CLpro) or the main protease (Mpro). Besides, one or two papain-like proteins are processed to produce 16 non-structural proteins (nsps) (49). The functions of the nsps are not completely obvious; but they probably participate in viral RNA synthesis, virus assembly, closing the host macromolecular synthesis, disable the host's innate immune response. The structural proteins such as $\mathrm{N}$ protein interact with the virion genomic RNA, then assembly of virus particles happens, finally, the nucleocapsid is formed. The nucleoid capsule grows inside the perinuclear membranes inside the endoplasmic reticulum. The mature virus particles are moved across the Golgi complex and get out of the infected cell through budding (11). Therefore, SARS-CoV-2 infects host cells, but conversely, nonenveloped viruses do not lyse cells personally (6). The cell-mediated immune arm of the adaptive immune system attacks contaminated cells and eliminates these cells; it is termly called a cytokine storm. The humeral immune arm hits the available viruses outside cells and locks them from invading other healthy cells. It is named neutralization. The innate and humeral adaptive immunity prevents from happening severe infections and it is the cell-mediated immunity system that destroys any lung cells infected with the virus (50). Heme is an essential part of hemoglobin. It is a porphyrin including iron. Firstly, the ORF8 binds to the porphyrin, then, ORF10, orflab, and ORF3a hit the heme that is on the 1-beta chain of hemoglobin, resulting in dissociating the iron to form the porphyrin. Gradually, as these attacks increase, hemoglobin decreases. Eventually, less oxygen and carbon dioxide are transferred into the bloodstream, which in turn contributes to the symptoms of suffocation (51). Other mechanisms by which the virus is involved have not yet been fully elucidated, and research is underway to find out.

There is a link between coronavirus infection and hypertension, there seems to be a direct link to Type 2 diabetes mellitus (T2DM). In the respiratory tract, ACE2 has the function of destroying angiotensin II to angiotensin 1-7 and acts to regulate the angiotensin system. By increasing ACE1 activity and inhibiting ACE2, angiotensin II binds to the angiotensin 1 (AT1R) or AT2R receptor, leading to inflammatory responses and stimulation of aldosterone secretion. As a result, not only does blood pressure rise but the risk of respiratory distress syndrome increases. In contrast, angiotensin 1-7 leads to anti-inflammatory responses that are desirable for the recovery of patients with COVID-19. People with COVID-19 have an imbalance in the activation of these pathways due to high blood pressure and insulin resistance and T2DM (52).

\section{Prevention and current pharmacological treatments}

No specific treatment is yet available for SARS-CoV-2, so it is important to prevent further spread of the new virus. When the $\mathrm{R} 0$ is from a disease above one, it means it can be transmitted very quickly and easily. While that of COVID-19 is about 2.2. Therefore, due to the limitations of medical and health facilities, the focus should be on prevention. The WHO has released some general recommendations to prevent infection, including avoiding touching the nose, mouth, and eyes by your hands, regular handwashing with soap for about 20 seconds, avoiding contact with people, disposable masks should completely cover the mouth and nose of people for 
prevention and be replaced every day, using latex gloves outdoors (53). Two meters should be kept away from people who have suspicious symptoms. Keys, cell phones, doors, and car handles should be disinfected regularly with an alcohol pad or disinfectant solution. SARS-CoV-2 is sensible to heat and ultraviolet rays. Moreover, this virus can be significantly inoperative by lipid solvents including ether $75 \%$, chlorinecontaining disinfectant, ethanol, chloroform except, and peroxyacetic acid. National Institutes of Health in the USA has stated that it is a steady virus for several days on surfaces (copper, cardboard, steel, plastic). So far various studies have looked at the persistence of the virus on different inanimate surfaces; it has revealed that the virus is persistent for at least up to 9 days on surfaces such as plastic and glass. The hopeful thing is that the virus will be inactivated by using disinfection substances to clean the surfaces, including $0.5 \%$ hydrogen peroxide, 62 to $71 \%$ ethanol, and $0.1 \%$ sodium hypochlorite. Other biocidal substances that have less effect are $0.02 \%$ chlorhexidine digluconate and 0.05 to $0.2 \%$ benzalkonium chloride (54). However, strengthening the immune system is effective by consuming citrus fruits, getting enough sleep and exercising, as well as eating fluids. Vitamin $\mathrm{C}$ with the role of antioxidant activity can probably decrease inflammation. Vitamin $\mathrm{C}$ improves immune cell function, vasopressor synthesis, endovascular function, and epigenetic immunologic modifications, thus, using it can help to prevent infection (55).

There is currently no precise treatment for the SARS$\mathrm{CoV}-2$, but research is ongoing. Since the virus is spreading, researchers are conducting several experiments on several drugs. Most of the medications and methods used during this period and clinical trials have been effective drugs against SARS, HIV, MERS, and influenza viruses, which it is hoped these drugs are effective in COVID-19, too. Oxygen therapy, antibiotics combination, antivirals, corticosteroids, and convalescent plasma are some types of conventional treatment for patients infected by SARS-CoV-2 (56). No specific treatment is yet available for SARS-CoV-2, so it is important to prevent further spread of the new virus. When the $\mathrm{R} 0$ of a disease is above one, it means it can be transmitted very quickly and easily. While that of COVID-19 is about 2.2. Therefore, due to the limitations of medical and health facilities, the focus should be on prevention. The WHO has released some general recommendations to prevent infection, including avoiding touching the nose, mouth, and eyes by your hands, regular handwashing with soap for about 20 seconds, avoiding contact with people, disposable masks should completely cover the mouth and nose of people for prevention and be replaced every day, using latex gloves outdoors. Two meters should be kept away from people who have suspicious symptoms. Keys, cell phones, doors, and car handles should be disinfected regularly with an alcohol pad or disinfectant solution. SARS-CoV-2 is sensible to heat and ultraviolet rays. Moreover, this virus can be significantly inoperative by lipid solvents including ether $75 \%$, chlorinecontaining disinfectant, ethanol, chloroform except, and peroxyacetic acid. National Institutes of Health in the USA has stated that it is a steady virus for several days on surfaces (copper, cardboard, steel, plastic). So far various studies have looked at the persistence of the virus on different inanimate surfaces; it has revealed that the virus is persistent for at least up to 9 days on surfaces such as plastic and glass. The hopeful thing is that the virus will be inactivated by using disinfection substances to clean the surfaces, including $0.5 \%$ hydrogen peroxide, 62 to $71 \%$ ethanol, and $0.1 \%$ sodium hypochlorite. Other biocidal substances that have less effect are $0.02 \%$ chlorhexidine digluconate and 0.05 to $0.2 \%$ benzalkonium chloride (54).

\section{Effective chemical drugs}

1. Remdesivir (GS-5734): The Function of this drug is blocking RNA-dependent RNA polymerases. Recent research on animal models and cell cultures has shown that Remdesivir can prevent the proliferation of coronaviruses, but it is not clear how it does so. The research surveyed the effect of this drug on the virus that leads to MERS. It was discovered that remdesivir blocks a specific enzyme needed for viral replication. Coronaviruses are increased by replicating their genetic material with an enzyme known as RNA-dependent RNA polymerase (57). Remdesivir is still searching in experimental cases. An investigation revealed some information showing that remdesivir is effective against the SARS-CoV-2 in Vero E6 cells (58). Based on the available scientific evidence to the FDA, it is sensible to consider remdesivir as an effective treatment for COVID-19 (59).

2. Chloroquine Phosphate: It is widely used as antimalarial medicine that has a significant antiviral effect (60). The action mechanism of this drug may include viral protein glycosylation, virus assembly, suppressing the viral RNA polymerase, new virus particle transport, and virus release $(58,61-64)$. It has been observed that very low concentrations have been very effective in dealing with SARS-CoV-2.

3. Hydroxychloroquine: this drug is being used as a clinical trial on AIDS treatment (61). In an up-to-date trial with patients on COVID-19 remedy has demonstrated antiviral activity in composition with the antibiotic azithromycin against SARS-CoV-2 in vitro and unchecked clinical studies (65).

4. Lopinavir-Ritonavir: This combination is approved for AIDS that can be utilized for adults and infants over 14 days of age (66). In fact, both medicines are HIV protease inhibitors. But they are also undergoing phase 2 tests for MERS (67). SARS-CoV-2 has a key enzyme for replication called Mpro. Lopinavir-Ritonavir may bind to this enzyme and hope to suppress coronavirus activity 
(68).

5. Favipiravir: This is an RNA-dependent RNA polymerase inhibitor for novel influenza. In addition to the influenza virus, favipiravir can control other RNA viruses such as flavi-, alpha-, filo-, bunya-, arena-, noroviruses (69). It inhibits viral RNA polymerase and prevents the replication of viral genes in the cell. The drug appears to have an antiviral effect on SARS-CoV-2 and other viruses (70). In an investigation in China, favipiravir had even more potent antiviral effect than that of lopinavir. Right now, this drug is under more investigation.

6. Ganciclovir: Cytomegalovirus infections are targeted by ganciclovir. In fact, it is a potent inhibitor for the cytomegalovirus (71).

7. Acyclovir/Penciclovir: Herpes simplex virus and Varicella-zoster virus are the main targets for acyclovir. It is a synthetic acyclic derivative that results in chain termination (72).

8. Ribavirin: Ribavirin is also called Umifenovir has a broad-spectrum of antiviral effects, but the main use of this drug is for influenza virus infections. Also, it has not shown noticeable adverse effects (73). Ribavirin is used only as an intravenous injection (74).

9. Methylprednisolone: It has already been used in COVID-19 patients in combination with oseltamivir and antibiotics. But there is still no conclusive evidence that methylprednisolone is effective, and more research is needed (29).

10. Nitazoxanide: Its role is to modulate the proliferation of bacteria and viruses. It is approved to use for treating the animal coronaviruses but is still under investigation for humans (75).

11. Nafamostat: This is a synthetic serine protease inhibitor, which is prescribed for Influenza, MERS, and Ebola. The main action of this drug is to prevent membrane fusion by decreasing the release of cathepsin B $(76,77)$. This drug is right now under investigation.

12. Oseltamivir: It is another remedy for influenza A and B. Oseltamivir decreases the spread in the respiratory tract by preventing the viral enzymes and blocking the release of viral particles from human cells (78). In a clinical trial for curing COVID-19, Oseltamivir is using with Chloroquine and Favipiravir right now(79).

13. Arbidol: It is also known umifenovir. Arbidol is applied to treat the influenza B and A viruses; it inhibits viral fusion with the host cell membrane, so the virus cannot enter into the cell. The only way to use this medicine is orally and considerably suppress SARS-CoV-2 (73).

14. Bevacizumab: It is a monoclonal antibody and its target is vascular endothelial growth factor (VEGF)(79). Bevacizumab may decrease the levels of VEGF caused by hypoxia of the infected respiratory tract epithelium, therefore, it might overcome the edema in COVID-19 patients (80).

15. Darunavir: Some surveys illustrated that darunavir in combination with cobicistat (81) Actually, darunavir is an HIV protease inhibitor, and cobicistat is a booster for enhancing the pharmacodynamics and pharmacokinetics of Darunavir (82). darunavir can inhibit SARS-CoV-2 infection in vitro by repressing viral replication (83).

16. Type II transmembrane serine protease (TMPRSS2) inhibitors: Because this receptor is one of the receptors involved in preparing and entering the virus into the host cell (84), it may be effective to block it (70).

17. Recombinant human interferon $\alpha 2 \beta$ : Due to its good effect on SARS and MERS diseases, it seems to be effective in treating patients with COVID-19. However, it needs to investigate in terms of its efficacy and safety (79).

18. Thalidomide: Antiinflammatory action, destroying mRNAs in blood cells, and enhancing interleukins secretion is the main role of thalidomide. Activating interleukins such as IL-12 can activate natural killer cells (85). It is supposed that thalidomide is used to evaluate its effect on COVID-19 (79).

19. Pirfenidone: It is used in curing patients with idiopathic pulmonary fibrosis diseases. This drug by IL- $1 \beta$ and IL-4 inhibition could play an important role in antiinflammatory and anti-oxidant effects. It also appears to have a significant effect on exposure to the SARS-CoV-2 (79).

20. Anakinra: It is a recombinant protein medication, which is approved for curing patients with Cryopyrin Associated Periodic Syndrome, Still's disease, and Rheumatoid Arthritis. This drug harnesses the IL-1 that expressed in different organs and tissues (86).

21. Danoprevir: It is a protease inhibitor for the treatment of hepatitis $\mathrm{C}$ and used in combination with ribavirin, peginterferon- $\alpha$, and ritonavir (87).

22. Fingolimod: it is an immunology modulator that is helpful in multiple sclerosis. It has been shown that using it with ventilator support could be healful for patients with ARDS, so, its efficacy is determining for COVID19.

23. Bromhexine: It is a transmembrane protease serine inhibitor for inhibition of the S-glycoprotein of MERS$\mathrm{CoV}$ and SARS-CoVfor viral entry. It is evaluating in terms of the efficacy with standard treatment in patients with COVID-19. 
24. Baricitinib: It is an enzyme inhibitor that is suggesting to use for COVID-19 treatment, but no clinical data is still revealed (88). This drug may cooperate to reduce combat cytokine release syndrome (CRS), viral entry, and virus particle assembly (89).

25. Brilacidin: It is an Innovation protein made similar to host defense peptide. It has begun to test against SARSCoV-2 in the middle of March 2020 (90).

26. Disulfiram: It seems that it can prevent the papain-like proteases of SARS; however, but no clinical and in vitro data exist for COVID-19 yet.

27. Eculizumab: It is a kind of monoclonal $\mathrm{IgG}$ antibody that attaches to complement protein C5, so it suppresses membrane attack complex. It has been evaluated in a clinical examination for COVID-19, but yet no data exist to support utilization(91).

28. Galidesivir (BCX4430): It is used to cure Ebola and other hemorrhagic fever virus infections. In fact, Galidesivir inhibits RNA polymerase.

29. Griffithsin: This is a potent HIV entry inhibitor that displayed effectively in vitro activity against SARS (92).

30. Nelfinavir: it is an HIV-1 protease inhibitor, so it may be effective against SARS-CoV-2, but no clinical information exists yet (93).

31. Teicoplanin: It is an antiviral for the staphylococcal infection that also has inhibitory effects on the MERS. Therefore, it is considered as a potential remedy to control the SARS-CoV-2 (94).

32. Baloxavir: This antiviral is active against influenza viruses and could be a potential drug. There is no published clinical trial in terms of its safety and effectiveness in the treatment of COVID-19 (95).

33. Atazanavir: This drug with ritonavir or alone is usually utilized for treating HIV. It has seen that azanatavir has activity against SARS-CoV-2 in Vero E6 cells in vitro (96).

34. Azithromycin: It belongs to the category of macrolides and has in vitro activity against viruses such as Zika and influenza. Although no clinical data currently exist, it can be used in combination with other drugs as its antiinflammatory and immunomodulatory effects (97).

35. Colchicine: This drug may fight the cytokine storm of COVID-19 by suppressing proinflammatory cytokines and chemokines. NOD-like receptor protein 3 (NLRP3) is responsible for the release of interleukins, in particular IL- 1及. 37 in acute respiratory distress syndrome. Colchicine can inhibit NLRP3 (98).

Drugs Tocilizumab, Corticosteroids, Leronlimab, and Sarilumab have also been used as adjunctive therapy (99-
101).

\section{Effective biological treatments}

\section{Convalescent plasma therapy (CPT):}

Immunoglobulins are helpful in several diseases (102). In this way, the body prepares the necessary antibodies to fight the virus in advance. Although, some viruses such as influenza viruses, Ebola virus (EBOV), HIV-1, and hepatitis $\mathrm{C}$ virus could mutate their superficial glycoproteins to avoid the antibody responses. Thus, using this kind of remedy has its obstacles (103). Currently, one of the ways to save people with COVID-19 is using blood plasma from those who have been cured of the disease. In an FDA-approved treatment plan, this method has been used, and doctors hope to use the plasma of patients who have recovered from COVID-19 to patients who are still in critical condition to help improve current patients (104). However, the amount of plasma available is less than the number of patients, so this method is currently used to treat critically ill patients (105). It has been observed that RNA of SARS-CoV-2 disappears completely by CPT therapy and neutralizing antibody titers rise, so mortality rate in severe COVID-19 patients reduces (106).

2. Interferons (IFNs): IFNs are a broad class of cytokines divided into type I, type II, and type III that release by the immune cells when subjected to infections, autoinflammatory, and autoimmune diseases (107). IFNs have antiviral activities initiated by their interactions with cognate receptors (108). Type I IFNs could effectively inhibit virus replication and activate immune cell subsets. Type I IFNs can be used alone or in combination with other therapies to treat chronic and acute viral infections due to its antiviral and immunomodulatory effects (109). Among the different types of type I IFNs, IFN- $\alpha$ is generally used to treat hepatitis $\mathrm{B}$ and $\mathrm{C}$ viruses. It binds to cellular surfaces' receptors and initiates signaling cascades, and finally, could inhibit the replication of vires. This antivirus has been used as an inhaler and injector for the treatment of COVID-19 (110).

3. Vaccines: Vaccines are effective weapons against infectious diseases caused by viruses. The isolation of the new coronavirus has led scientists to think about produceing a new vaccine, but the chances of success due to various processes in the development and final approval of a vaccine are low (111). Five technical routes including recombinant genetically engineered vaccines, nucleic acid vaccines, inactivated vaccines, vaccines made from attenuated influenza virus vaccine vectors, and adenovirus vector vaccines for the development of SARS-CoV-2 vaccines have developed by scientists (112). At present, there are 10 candidates for COVID-19 vaccines that are examining; 
ChAdOx1 nCoV-19 (Moderna), mRNA-1273 (University of Oxford), bacTRL-Spike (Symvivo Corporation), LV-SMENP-DC (Shenzhen GenoImmune Medical Institute), Adenovirus Type 5 Vector (CanSino Biologics Inc), Pathogen-specific aAPC (Shenzhen Geno-Immune Medical Institute), INO4800 (Inovio Pharmaceuticals), BNT162 (BioNTech), and two vaccines developed by Wuhan Institute of Biological Products and Sinovac Biotech. on May 22, 2020, the first-in-human trial of a recombinant adenovirus type-5 (Ad5) vector COVID-19 vaccine was reported and the results revealed that The Ad5 vectored COVID-19 vaccine was well immunogenic at 28 days after vaccination (113). Also, on August 15, 2020, The Lancet journal published the results of randomized, double-blind, placebo-controlled, phase two trial of the Ad5-vectored COVID-19 vaccine to determine the appropriate dose of this vaccine, indicating that the vaccine at $5 \times 1010$ viral particles was safe and induced the immune responses (114).

4. CD24Fc: CD24 is a glycosylated membrane protein expressing in granulocytes, immature B and T cells, some epithelial cells, and macrophages. CD24 can play a regulatory role in the homeostasis of $\mathrm{B}$ and $\mathrm{T}$ cells (115) and decrease the immune response of the host against proteins released by damaged cells. Thus, it is another molecule that can control the inflammatory response related to SARS-CoV-2 infection. CD24Fc is a recombinant fusion protein consisting of $\mathrm{CD} 24$ attached to the Fc region of human IgG1. Preclinical studies have demonstrated that CD24Fc relieves the graft-versus-host disease by decreasing TNF $\alpha$, IL1 $\beta$, and IL6 release (116). Therefore, according to these data, a biological reason has been provided for conducting a CD24Fc clinical trial on COVID-19, and at present, a randomized, double-blind, placebocontrolled, phase 3 study is performing on severely ill infected patients [NCT04317040] (117).

5. Mesenchymal stem cells: It is a cell-based approach to moderate the damage resulting from inflammation in COVID-19 and is represented by allogeneic mesenchymal stem cells (MSCs). MSCs are multipotent cells with reparative that have immunomodulatory properties, they are isolated from different tissue types (118). MSCs have protective effects by secretion of multiple paracrine factors such as anti-inflammatory cytokines (119). Based on A clinical trial, it was indicated that allogenic MSCs transplantation was safe in 7 COVID-19 patients (120). Also, another study examined exosomes efficacy and safety resulted from allogeneic bone marrow MSCs in moderate-to severe acute COVID19 patients. Exosomes contain a variety of growth factors, cytokines, microRNAs, and mRNAs; they mediate regenerative, anti-inflammatory, and immunomodulatory properties of MSCs. Based on this study, the survival rate was $83 \%$, oxygenation was increased, and coagulation parameters, inflammatory, and leukocyte count were changed. All these results approved that MSCs had a positive impact on the cytokine storm of SARS-CoV-2 (121).

\section{Effective natural herbs}

China recommends using herbal treatments for the SARSCoV-2, but not all scientists agree. Dr. Edzard Ernest of United Kingdom's University warns that these drugs pose two direct and indirect risks to patients. According to the National Health Commission of China, 90\% of people with COVID-19 use herbal remedies for their treatment. Traditional Chinese medicine (TCM) uses phytochemical compounds in different forms such as pills, teas, tinctures, powders, and so on (83). Luo et al., analyzing the frequency of TCM in 23 provinces, concluded that 10 main and important drugs in traditional Chinese medicine are helpful to treat SARS-CoV-2, including Glycyrrhizae uralensis, Astragalus membranaceus, Rhizoma Atractylodis Macrocephalae, Saposhnikoviae divaricate, Fructus forsythia, Lonicerae Japonicae Flos, Radix platycodonis, Atractylodis Rhizoma, Cyrtomium fortune J. $\mathrm{Sm}$ and Agastache rugose (122). According to research by $\mathrm{Xu}$ et al, Yu Ping Feng and Astragalus membranaceus have been used in coronavirus-2 prevention programs. These drugs strengthen the immune system. Medicinal plants used in northern China include Agastache rugosa and Atractylodis Rhizoma. Medicines used in southern China included medicinal plants with aromatic dehumidification properties (123). Liu has stated that the most important medicinal plants for the treatment of COVID-19 include: qinggan capsules, lianhua qingwen capsules, and shufeng jiedu capsules. Also, qingfei touxie fuzheng, gancaoganjiang decoction, sheganmahuang decoction, and qingfei paidu decoction (QPD) are some effective recipes of TCM. QPD has been one of the most important medical prescriptions used during last few months, which consisted of Glycyrrhizae Radix et Rhizoma Praeprata cum Melle, Ephedrae Herba, Armeniacae Semen Amarum, Cinnamomi Ramulus, Gypsum Fibrosum, Alismatis Rhizoma, Poria, Bupleuri Radix, Polyporus, Atractylodis Macrocephalae Rhizoma, Scutellariae Radix, Zingiberis Rhizoma Recens, Pinelliae Rhizoma Praepratum cum Zingibere et Alumine, Asteris Radix et Rhizoma, Farfarae Flos, Dioscoreae Rhizoma, Belamcandae Rhizoma, Asari Radix et Rhizoma, Aurantii Fructus Immaturus, Pogostemonis Herba, and Citri Reticulatae Pericarpium (124).

Several Chinese herbs have been also suggested to be used by some patients to prevent SARS-CoV-2, including Shu Feng Jie Du Capsule, Huo Xiang Zheng Qi Shui, and Jin Hua Qing Gan Granule. Drugs used during clinical therapy include: Re Du Ning Injection, Xue Bi Jing injection, Qing Fei Pai Du Tang, Xing Nao Jing Injection, Xi Yan Ping Injection, Tan Re Qing Injection and some formulas of 
traditional Chinese medicine should be taken with these drugs (56). Sheng Mai Injection, Gong Niu Huang Pill, Shen Mai Injection, Shen $\mathrm{Fu}$ Injection, and a $\mathrm{Su} \mathrm{He}$ Xiang Pill are also used in patients in critical condition. Some other medicinal herbs suggesting to test in order to prevent and treatment of COVID-19 are dried rhizome of Curcuma longa L. This herb has antiviral activities against herpes simplex virus and HIV, therefore, it can also have inhibitory effects in terms of SARS-CoV-2 entry into the host cell (125).

\section{Pharmacological and natural combination treatment}

Dr. Lei Guan Shi, head of the Chinese Medicine Department at Corona's Guan Man Hospital in Beijing, explained the symptoms of the disease from the perspective of Chinese medicine, noting that most patients benefit from a combination of conventional medicine and traditional medicine in China. It is important to control the disease in the first week and prevent it from entering a critical phase. In this regard, the combined use of chemical and herbal medicines has had a significant impact, and a high percentage of patients undergoing combination therapy with traditional medicine and they are common medicine, they have improved. He said that herbal medicines also help to increase the effectiveness of chemical medicines, adding that there are several herbal medicines for the treatment of corona in this country and specified: Herbal medicines have been used to boost the immune system and reduce inflammation and edema in patients' lungs, and in some cases, acupuncture has been used.

Previous experiments to treat SARS and MERS have been successful with the simultaneous use of common medicine and herbs. As a result, the Chinese scientists took the first steps to treat the COVID-19 with these two methods. In some surveys, TCM and conventional medicine are combined for assessing the effect on patients with COVID-19. Drugs that are using include antiviral drugs such as IFNa-2b and ribavirin a-interferon, antibiotics such as azithromycin and moxifloxacin, and human immunoglobulin. Chinese herbs using include mixtures of different herbs, single herbs, and Chinese proprietary medicines. Each of the three types can be combined with western medicines, separately. The mixture of herbs prescribed to combination with drugs depends on the patient's symptoms (126).

\section{In Vitro studies}

The most important IVD test for SAS-CoV-2 is RT-PCR that takes a few hours to perform. It takes 45 minutes for an IVD assay with a Cepheid. Interestingly, POC molecular assay by Abbott was reduced the assay time to 5 minutes. Most of the molecular tests by the FDA, EUA, and CE have been affirmed. Many serological assessment methods, along with molecular methods, are used to diagnose SAS-CoV-2. Many serological assessment methods, along with molecular methods, are used to diagnose the virus. The most significant serological methods are manual ELISA, automated chemiluminescent IA, and rapid lateral flow IA. These methods detect IgG and IgM produced in people infected with coronavirus-2. Three teams of investigators are developing serologic tests to answer key questions about SARS-CoV-2. Guo and colleagues looked at the kinetics of immunoglobulin $\mathrm{M},(\mathrm{IgM}), \operatorname{IgA}$, and $\operatorname{IgG}$ antibody response in infected patients using an ELISA based on COVID-19 viral nucleocapsid protein. The researchers assessed 208 plasma samples from 82 confirmed and 58 probable COVID-19 cases (127). Antibodies were found as early as 1 day after the start of symptoms. IgM ELISA detected more cases than polymerase chain reaction (PCR) on day 5.5 of sickness. The combination of IgM ELISA plus PCR detected $98.6 \%$ of cases versus $51.9 \%$ with a single PCR. During the first 5.5 days, PCR had a higher positivity rate than IgM; the reverse was true after day 5.5. No cross-reactivity was found with common coronaviruses that cause upper respiratory infections. In a family cluster, PCR-negative family contacts of COVID-19 cases had positive serologic assay, confirming the presence of antibodies in asymptomatic infection. Zhao and colleagues assessed the IgM antibody, IgG antibody, and total antibody against SARS-CoV-2 on serial blood samples obtained from 173 patients (median age, 48 years) with PCR-confirmed COVID-19 in Shenzhen, China. Plasma samples were tested using ELISA kits prepared by Beijing Wantai Biological Pharmacy Enterprise Co in China (128). In samples collected during the first 7 days after illness onset, positive rates were $66.7 \%$ for PCR and $38.3 \%$ for antibody assays. During the second week after illness onset, positive rates were $54.0 \%$ for PCR and $89.6 \%$ for antibody assays. The combined use of PCR and antibody testing improved the identification of positivity through various phases of illness. Increases in antibody levels were not associated with RNA clearance, including in three patients with a critical illness. A strong correlation was found between antibody titer and clinical severity for more than two weeks following illness onset. The total antibody was more sensitive than $\operatorname{IgG}$ or $\operatorname{IgM}$ antibody. $\mathrm{Li}$ and colleagues developed a lateral flow immunoassay that detects IgM and IgG antibodies simultaneously and can test finger-prick blood, plasma, and serum. The point-of-care test provides results within 15 minutes and requires no special equipment. The assay was tested in six provinces in China on blood samples from 397 COVID-19 patients which were confirmed by PCR and on 128 negative cases (129). However, in COVID-19 patients, the number of white blood cells may fluctuate. Leukocytosis, Leukopenia, and lymphopenia have been notified, though the most typical manifestation is lymphopenia. High levels of aminotransferase have also been reported in these patients. At the time of hospitalization, most pneumonia patients have standard serum procalcitonin levels; although, their levels are likely to be higher in people who need intensive care (ICU). In one study, high levels of D-dimer and further severe lymphopenia were associated with mortality (130).

There is evidence for the ability of Chloroquine and 
Hydroxychloroquine to inhibit SARS-CoV-2 in vitro. Liu et al. obtained a similar $50 \%$ cytotoxic concentration $\left(\mathrm{CC}_{50}\right)$ for both drugs. Irrespective of the multiplicity of infection (MOI), the $50 \%$ maximal effective concentration $\left(\mathrm{EC}_{50}\right)$ of Chloroquine (CQ ) is lower than Hydroxychloroquine (HCQ) (131). According to research by Yao et al. (1) in vitro, it was identified that HCQ was more effective than $\mathrm{CQ}$ in eliminating coronavirus-2 (the HCQ $\mathrm{EC}_{50}$ of $0.72 \mu \mathrm{M}$ and $5.47 \mu \mathrm{M}$ for $\mathrm{CQ}$, and is $\mathrm{MOI}=0.01$ ). In a study conducted by Wang et al., The antiviral activity of chloroquine was identified in vitro. The $\mathrm{CC}_{50}>100 \mu \mathrm{M}$ at an MOI of 0.05 and $\mathrm{EC}_{50}$ of $1.13 \mu \mathrm{M}$. In this study, they ascertained that chloroquine had high selectivity for coronavirus-2 instead of host cells (132). Lopinavir has shown in vitro activity against SARS-CoV, and a study of lopinavir plus the protease inhibitor ritonavir demonstrated clinical efficacy for human SARS. To evaluate whether lopinavir-ritonavir would be effective for COVID-19, investigators conducted an openlabel randomized trial at a single hospital in Wuhan, China, beginning on January 18, 2020. They assigned 199 adult patients with COVID-19 infection, radiographically confirmed pneumonia and oxygen saturation of $<94 \%$ or partial pressure of oxygen $<300 \mathrm{~mm} \mathrm{Hg}$ to receive standard care alone or with oral lopinavir-ritonavir (400 mg-100 mg) twice a day for 14 days. Lopinavir-Ritonavir and standard caregivers do not differ significantly in clinical improvement over time (16 days), duration of intensive care unit stay, days of mechanical ventilation, or days of oxygen support. Patients who received lopinavir-ritonavir had lower 28-day mortality (19\% vs. $25 \%$ ), but the between-group difference was not significant. SARS-CoV-2 RNA concentrations in throat swabs obtained over time did not differ between the two groups (133). The Lopinavir-Ritonavir test was performed in adults hospitalized with severe COVID 19. 199 patients were randomly selected for this study. 99 were in the LupinavirRitonavir treatment group and 100 were in the standard care group. There was no difference between patients taking lopinavir and ritonavir and patients in the standard care group. People who used Lupinavir-Ritonavir recovered one day earlier. Gastrointestinal side effects were more frequent in patients taking lopinavir-ritonavir, but serious side effects were more prevalent in cases in the standard care group (133). In one study, SARS-CoV-2 inhibition was investigated by Remdesivir and Chloroquine in vitro. The study found that the drugs were effective in controlling COVID-19. These drugs are used in patients with a safety track record and be effective against various diseases. Therefore, it is recommended that these drugs be used to treat patients with coronavirus-2 (134). Another study examined the effects of Lopinavir/ritonavir versus Favipiravir on the treatment of coronavirus-2 in vitro. Several patients received oral Favipiravir plus (IFN)- $\alpha$ by aerosol inhalation and others treated with Lopinavir/ritonavir plus IFN- $\alpha$ by aerosol inhalation. The study found that Favipiravir was more effective in treating coronavirus-2 (135).
However, another suggested therapy is immunopathogenesis that needs to be more surveyed. Any action to help the immunomodulatory effect of T-helper2 may help ill patients to reduce the damaging consequence of inflammatory pneumonia. Interleukin-10 inhibits IFN-gamma TNF-alpha, and IL-12 so the immune system polarizes towards T-helper2 and away from T-helper-1 (136).

\section{In Vivo studies}

Experimental evidence regarding the effect of $\mathrm{CQ} / \mathrm{HCQ}$ on the treatment of COVID-19 is currently very limited. The first clinical results were released from the Chinese government in February 2020 that reported treatment of more than 100 patients with chloroquine phosphate in China led to significant improvements in pneumonia and lung imaging and a reduction in disease duration. No side effects have been stated. These findings came from several pooled continuous trials utilizing a variety of study patterns. So far, no experimental data have been published to support these findings. In the clinical trial by Gautret and colleagues in France On the $17^{\text {th }}$ of March 2020 (65), 36 patients with COVID-19 were examined. Six of them had no symptoms while 22 patients had symptoms of upper respiratory tract infection and eight people had symptoms of a lower respiratory tract infection. For 10 days, twenty patients received 200mg of HCQ three times a day. For six people, azithromycin was also prescribed to prevent bacterial superinfections. The control group had normal care. The principal result of the test was the SARS-CoV-2 carrier on Day 6, experimented using the PCR technique on nasopharyngeal swabs. The results of the treatment group of patients tested on the sixth day were noticeably negative compared to those in the control group. The test of six patients who had received simultaneously azithromycin and HCQ was negative on Day 6. The researchers believe that the combined treatment of HCQ and azithromycin has remarkable effects on the treatment of patients. According to the positive results of the first clinical trials, official guidelines for the treatment of coronavirus- 2 were published using CQ and HCQ drugs.

The National Health Commission of the People's Republic of China announced in mid-February that it would recommend that the patients use $500 \mathrm{mg}$ of chloroquine phosphate (300 mg for CQ) twice a day be treated for a maximum of 10 days (70). On the 17th of March, the L. Spallanzani National Institute in Italy suggested treatment for coronavirus-2. The recommended treatment was $400 \mathrm{mg}$ HCQ per day or $500 \mathrm{mg}$ CQ per day with another antiviral drug (137). Controlling cytopathy at a concentration of 1 $(\mathrm{mg} / \mathrm{l})$ Lupinavir with ribavirin at $6.25(\mu \mathrm{g} / \mathrm{ml})$ and collected information suggest that the compound may be synergistic against coronavirus-2 in vivo (74). An in vivo investigation of MERS revealed that $\mathrm{EC}_{50}$ values made for lopinavir were 11.6, $\mathrm{CC}_{50}$ values $>50 \mu \mathrm{M}$, the $\mathrm{SI}$ was $>4.3$, and $\mathrm{EC}_{50}$ values generated for ritonavir $24.9 \mu \mathrm{M}$ with $\mathrm{CC}_{50}$ values $>50 \mu \mathrm{M}$, 
the SI $>2$ (138). The study of Sheahan et al found that both prophylaxis and treatment with Remdesivir had protective effects against MERS-CoV proliferation and associated pathology. In general, they suffer less lung damage than the control group, and their pulmonary function is better. Among the mice tested, those who took Remdesivir the day before the infection had a six-day better survival than those who did not receive Remdesivir (138).

\section{In Silico studies}

Regarding the fact that SARS-CoV-2 has caused a pandemic and lack of efficacious vaccine/drug, in silico studies play an important role in testing whether existing drug-like compounds are effective against viral infections or not and it can help health workers to use the best treatment against this virus. Therefore, the in silico studies were collected and the effective herbal and chemical drugs against this virus discussed. SARS-CoV-2 genome is translated into polyproteins that have been processed by its protease enzymes. These proteins are prime antiviral targets. In fact, the crucial role of 3CLprotease or Mpro makes this enzyme as the most promising target. In silico and genomic structural features of novel coronavirus showed that it is closely like the SARS coronavirus and it suggests that traditional Chinese medicine (TCM) may be useful in the current outbreak (5) because treating patients with the severe acute respiratory syndrome (SARS) who were treated with TCM in 2003, resulted in the shorter length of hospitalization, decreased steroid-related side effects, and improvement of symptoms (139). In this issue of the Journal of Integrative Medicine, Zhang et al., provided in silico methods to narrow down TCM remedies that may directly inhibit the coronaviral reproduction. In this study, integrative model of absorption, distribution, metabolism, and excretion (ADME) was used to screen natural compounds that may be bioactive via being administrated orally and also molecular docking software AutoDock4 was used to perform protein compound docking analysis and finally it was shown that 13 natural compounds have potential anti-2019-nCoV activity and 125 Chinese herbs contain 2 or more of these compounds (140). Moreover, a library of 100 FDA approved antiviral compounds and 1000 active phytochemicals have been screened through PyRx and autodock-Vina virtual screening tools in which Nelfinavir displayed the highest binding affinity $-8.4 \mathrm{Kcal} / \mathrm{mol}$ and strong and stable interactions with the amino acid residues present on the active site of COVID-19 Main Protease. Besides, drugs including Rhein, Withanolide D, Withaferin A, Enoxacin, and Aloe-emodi also showed a good binding affinity with favorable ADME properties respectively (141).

The biological activity of seven popular anti-malarial compounds as a ligand of COVID-19 protease including mepacrine, quinine, chloroquine, hydroxychloroquine, phomarin, artemisinin, and proguanil have been assessed and compared by $\log \mathrm{P}$ and $\log \mathrm{S}$ values and based on the binding affinity of these drugs, it has been revealed that epacrine appears as the most powerful inhibitor among other six compounds. Other potential inhibitors of COVID-19 protease are chloroquine, hydroxychloroquine, and phomarin (142). In addition, using the SwissDock web-based on the EADock ESS docking algorithm and ALOGPS 2.1 program which is based on the electro-topological state indices and associative neural network modeling, it has shown that 11 different species of Indian medicinal plants, more particularly those with anti-viral, anti-malarial or other similar activities have inhibition properties against COVID-19 protease. On the other hand, lipophilicity, aqueous solubility, and binding affinity of the extracted compounds suggest the most inhibition potentials in harsingar, aloe vera, giloy, turmeric, neem, ashwagandha, red onion, tulsi, cannabis, and black pepper respectively. Notably, inhibition potentials of the extracts of harsingar, aloe vera, and giloy are very encouraging in comparison with binding affinity with hydroxychloroquine (143). In another docking and molecular dynamics study, it has been revealed that Flaviolin which is a fungal metabolite can interact with one of the important target proteins of SAR-CoV2, 3CLpro, and block its function (144). Based on a study conducted by Rimanshee Arya et al., in which the catalytic domain of PLpro has been delineated by comparing it with the known sequences of other coronaviruses., sixteen FDA approved drugs, namely formoterol and chloroquine were found to bind the target enzyme with significant affinity and good geometry, signifying their potential to be applied against 2019 novel coronavirus (145). Using the CASTp server, the active site pocket in the 'SARS-CoV2 E' protein was calculated (146). Active pocket with the highest volume as well as area was considered for molecular docking studies with phytochemicals having 250 conformations $(147,148)$ via the AutoDock (149) tool. After binding human 'SARA-CoV E' protein with three phytochemicals namely Belachinal, Macaflavanone E, and Vibsanol B, the random motion of the human 'SARS-CoV2 E' protein gets decreased; this, in turn, stops the human "SARS-CoV2 E" protein function. As Belachinal, Macaflavanone E \& Vibsanol B, have passed the ADMET test and 'Lipinski's Rule of 5s', they may be consumed in controlling disease caused via SARSCoV2, after further in vitro and in vivo investigations (150).

Using PyRx 0.8, virtual screening of pharmacologically active compounds has been performed in order to recognize new potential antiviral drugs against 3CLprotease or main protease (Mpro) of SARS-CoV-2 which is the major proteolytic enzyme of SARS-CoV-2 and cleaves nsp4-nsp16. All the drug-like molecules have been gained from LOPAC1280 drug library (Library of Pharmacologically Active Compounds, Sigma-Aldrich, St. Louis, MO). Among 1280 compounds, the top 10 molecules including Etoposide, BMS_195614, KT185, Idarubicin, GSK 121015A, WIN_62577, Eptifibatide_acetate, KT203, SB_202190, and GR_127935 were showing good binding efficacy. Molecular 
docking of the top 5 selected screened compounds was carried out using AutoDock 4.2.6. finally, it was shown that all identified molecules were capable of interacting with His41 residue which is the key site for catalytic activity (151). In addition, it was found that KT185, KT203, BMS_195614, GSK1210151A, Eptifibatide acetate, and GR127935 hydrochloride hydrate drug molecules were able to inhibit the spike-ACE2 interaction at virus entry step (152). Therefore, these molecules can be better antiviral candidates because of their inhibitory action at both virus-host cell receptor interaction and post-translation step of non-structural proteins. However, a new drug made up of the morpholino based drug coupled with physcion was designed by using Chemsketch free software and further selected for molecular docking study. Notably, designed ligand structures are closely similar to the structure of Remdesivir with slight modification i.e., nucleoside analog has been replaced with morpholino analog. The in silico study revealed that this drug has a high potential of virus RNA Dependent - RNA polymerase inhibition with minimum binding energy (153).

In a study, an online tool "ZINC-pharmer" from ZINC database was used for pharmacophore-based virtual screening of around 1500 drug-like compounds (154). For further evaluation of these drug-like compounds, all the retrieved compounds were screened by molecular docking-base and it was docked with Mpro of SARS-CoV-2. Then, using the Molecular Operating Environment (MOE) system, the selection of screening ligand complex was done with Mpro based on Score (higher than reference inhibitor) and rootmean-square deviation (RMSD) value. Among near 200 compounds which were identified having strong interaction with Mpro of SARS-CoV-2, three compounds (ZINC20291569, ZINC90403206, and ZINC95480156) showed highest binding energy with Mpro of SARS-CoV-2 and strong inhibition effect than the reference inhibitor which can suggest greater potential to stop the replication of SARS$\mathrm{CoV}$ and curing COVID-19 subsequently (155). In another pre-printed in silico study, flavonoids have been screened against novel drug target, Mpro, of SARS-CoV-2 for the identification of Mpro inhibitors to provide natural scaffolds for drug development. Performing virtual screening-based molecular docking, it was shown that binding affinity of flavonoids such as hesperidin and rutin to Mpro of COVID19 is better than Nelfinavir. Potent of flavonoids can be ranked based on moldock binding score. According to this score, hesperidin, rutin, diosmin, apiin, diacetylcurcumin have the most affinity respectively (156).

In another pre-printed article, as Hepatitis-C virus (HCV) and SARS-CoV-2 are both +ssRNA viruses, molecular interactions between FDA-approved antiviral drugs against the HCV (including beclabuvir, tegobuvir, dasabuvir, deleobuvir, setrobuvir, radalbuvir, lomibuvir, remdesivir, uprifosbuvir and favipiravir) and RNA-dependent RNA polymerase ( $\mathrm{RdRp}$ ) of SARS-CoV-2 have been investigated. using InterPro Scanner, the amino acid sequence of the viral RdRp was scanned for the identification of known functional domains/motifs (157). Homology modeling of the RdRp was carried out through SwissModel and quality was checked using PROCHECK. Then, Rigid-body molecular docking between several established antiviral drugs and RdRpSARSCoV-2 was carried out using AutoDock (v4.2). Molecular docking studies were visualized by PyMol, (158). Finally, it was shown that antiviral drugs for HCV could be utilized as anti-SARS-CoV-2 drugs and Beclabuvir which is a nonnucleoside inhibitor of the RdRpHCV is the best one among other ones because it can efficiently bind to RdRp SARSCoV-2 and also showed better binding free energy (159). Another study has been designed to predict a protein-based drug for SARS CoV 2. The RNA sequence of that virus was extracted from NCBI. Also, the serface glycoprotein sequences were retrieved from NCBI and genbank. Then, the protein structure was predicted with swiss model and phyre 2 protein structure prediction tools. The predicted spike glycoprotein had a docking function with the human ACE2 receptor which was shwon by using Hex 8.0 docking tool. The proposed amino acid sequence of FC region $\mathrm{IgG} 1$ and human ACE2 receptor are taken and fused as amino acid sequence. Fc region IgG1 has a vital immunological response and helps curing the disease. SARS CoV 2 SPIKE GLYCOPROTEIN and ACE2-FC region IgG1 both have a bonding and docking ability. This protein complex can be considered as a potential neutralization drug against SARS CoV 2 virus (160).

In a study conducted by $\mathrm{Chi} \mathrm{Xu}$ et al. in 2020, 28 putative viral proteins encoded in its genome were listed in order to use the best available structures for screening. Then, small peptides and other 10 proteins were removed from the list as there was no structure for either SARS or SARS-CoV-2. Among other remained proteins, S protein and nsp5 of SARSCoV-2 have structures deposited in the protein data bank (PDB) with PDB ID 6CS2 and 6LU7, respectively. The remaining viral proteins shared high sequence identities with their SARS counterparts, ranging from $76.60 \%$ in nsp3 to 99.84\% in nsp13, except nsp4. Finally, 14 structural models were built and followed by molecular dynamics refinement and simulation for optimized protein structures. In addition, FDA-approved drugs and drugs currently in clinical trials in DrugBank were selected for virtual screening. A list of active sites from structures of the 16 viral proteins and ACE2 protein (PDB ID: 6CS2) as the ligand targets for screening were selected. In fact, this study evaluates current candidate drugs based on structures of viral proteins and human ACE2 receptor. Besides, the binding energies for nsp5 (Mpro), nsp14, and nsp15 were generally low as the surface geometry and hydrophobicity of the active sites make them more suitable as a drug target. The drugs introduced on the top of the list were anti-HIV drugs, anti-HCV drugs, influenza virus antagonists, chemotherapeutic drugs, and asthma drugs. Anti- 
HIV drugs divided into enzyme inhibitors and dideoxynucleoside. Nucleoside reverse transcriptase inhibitors (NRTIs), including Tenofovir and Emtricitabine, may work insufficiently in coronaviruses because coronavirus is positive-sense single-stranded RNA virus which lacks nucleoside reverse transcriptase, and this is also reflected in the docking of this study as most of them ranked at the bottom with low binding affinity. Among the enzyme inhibitors of HIV in docking results of this study, Lopinavir, Dolutegravir, and Raltegravir showed a strong binding affinity with multiple target sites, especially at the catalytic sites of main protease and exonuclease which suggests their potential of clinical drugs in the treatment of COVID-19. Saquinavir, a multi-target inhibitor of SARS-CoV-2, shows a strong affinity with the main protease of SARS-CoV-2. Based on the results of this study, Beclabuvir, Saquinavir, Bictegravir, and Dolutegravir were recommended to be tested in clinical trials. Beclabuvir, used in the treatment of $\mathrm{HCV}$ infection, was one of the drugs which performed the best in the docking with low binding energy of-10.4 to nsp5. Also, strong hydrogen bonding, $\pi-\pi$ stacking and hydrophobic interactions implies that this drug may be a stronger exonuclease inhibitor of nsp15 rather than Lopinavir. Saquinavir, Bictegravir, and Dolutegravir are antiretroviral drugs used for the treatment of HIV infection. Saquinavir has a binding energy of- $9.9 \mathrm{kcal} / \mathrm{mol}$ to nsp5. The binding energy of Dolutegravir and Bictegravir to nsp5 are very similar (-8.9 and -9.5 respectively). Surprisingly, all these three drugs are in the category of protease inhibitors. These resemblances make it hopeful to consider them as a potential treatment of COVID-19. Interestingly, other enzyme inhibitors of HIV like Ritonavir, Tipranavir, Elvitegravir, Nelfinavir, Darunavir, and Fosamprenavir have a relatively low binding affinity with the chosen targets in the docking of this study. Six anti-HCV drugs including five RdRp (NS5B of HCV) inhibitors, including Filibuvir, Bictegravir, Ribavirin-monophosphate, Sofosbuvir, and one protease (NS3/4B) inhibitor - Bictegravir are also among best-performed drugs. It is noteworthy that Bictegravir has a profound strong affinity with Mpro (binding energy-10.4 kcal $/ \mathrm{mol}$ ), nsp13 (binding energy $-9.8 \mathrm{kcal} / \mathrm{mol}$ ), nsp14 (binding energy $-8.8 \mathrm{kcal} / \mathrm{mol}$ ) and nsp15 (binding energy $-8.3 \mathrm{kcal} / \mathrm{mol}$ ) and it makes this drug as one of the best-performed drugs in the docking of this study. The comprehensive score of filibuvir does not fall far behind the score of Bictegravir and even exceeds in some docking sites. Therefore, anti-HCV drugs should be tested for fighting against SARS-CoV-2. Tivantinib, Lifirafenib, Entrectinib, Nilotinib, and Radotinib, the chemotherapeutic drugs and Montelukast and Zafirlukast which are used in the treatment of asthma are also on the top of the list. The docking result also reveals the low binding energies of oseltamivir with different targeted proteins of SARS-CoV-2. Moreover, it was shown that Lopinavir, an anti-HIV drug in the category of a protease inhibitor, maybe a potent drug through inhibiting nsp15. Also, it has been predicted that Remdesivir, a nucleotide analog used for the antiviral purpose, binds to nsp14, nsp5, and nsp13 with low binding energy (-8.3 $\mathrm{kcal} / \mathrm{mol},-7.4 \mathrm{kcal} / \mathrm{mol}$ and $-7.2 \mathrm{kcal} / \mathrm{mol}$, respectively). It is noteworthy that strong Hydrogen bonds, $\pi-\pi$ stacking and hydrophobic interactions between the ligand and protein make Remdesivir as a potent inhibitor. On the other hand, the binding affinity of Remdesivir with RdRp (binding energy$6.3 \mathrm{kcal} / \mathrm{mol}$ ) is lower than that with endonuclease (binding energy- $8.3 \mathrm{kcal} / \mathrm{mol}$ ), likely to the difficulty to choose the right key residues in this interaction. Finally, the effect of two natural products (Quinine and Doconexent) has been observed in this study. Quinine, an anti-malarial drug, had binding energy of-7.5 $\mathrm{kcal} / \mathrm{mol}$ against nsp13, which is comparable to some of the drugs used in clinical trials. It can be a potential inhibitor due to its interaction with nsp13 including hydrogen bonding, $\pi-\pi$ stacking food supplement, and hydrophobic interactions. Doconexent, a mixture of fish oil and primrose oil which has minor anti-inflammatory effects, is ranked at the bottom of the half against all active sites and it can be due to lack of $\pi-\pi$ stacking while it has low binding energy with nsp14 (-6.7 kcal/mol) (161).

In an in silico study, after investigating the inhibitory effect of 21 selected compounds on Chymotrypsin-like protease (3CLpro) called also the main protease (Mpro) (12) by blind and specific docking experiments and performing molecular docking by AutoDock Vina program on molecules obtained from PubChem database, it has been revealed that three molecules (hispidin, lepidine $\mathrm{E}$ and folic acid) could bind tightly with the enzyme (162). Another study examined the tendency of 1033 medicinal herbal compounds to ACE2, TMPRSS2, GRP78, and AT1R receptors, and found berbamine, hypericin, and hesperidin had the highest affinity. This study also examined hsa-miR-1307-3p and its tendency to inhibit the virus genome (163) . It is worth noting that His41, Cys145, and Glu166 are important residues in the substrate-binding subsite $\mathrm{S} 1$ for the proteolytic activity and the involvement of these residues is effective in forming hydrogen bonds which is important for the inhibitory impact of the Mpro. The best molecule is hispidin because the blind docking shows that $100 \%$ of poses are in the active site, it forms a strong hydrogen bond network with nCoV-2019 protease, six hydrogen bonds have been observed in both blind and specific docking and the binding affinity to the $2019-\mathrm{nCoV}$ protease is- $7.2 \mathrm{Kcal} / \mathrm{mol}$. The second molecule is lepidine E. $76 \%$ of poses are in the active site. Lepidine E bind tightly with the 2019-nCoV protease residues with a binding affinity-7.8 kcal/mol. A very strong and short hydrogen bond has been observed between hydroxyl groups of lepidine $\mathrm{E}$ and Leu141 with length of $1.64 \AA$ and $1.74 \AA$ in blind docking and specific docking respectively. The third best molecule is folic acid. The blind docking implies that $90 \%$ of poses are in the active site with a binding affinity of$7.6 \mathrm{kcal} / \mathrm{mol}$ and different positions have been verified in specific docking but all positions contain hydrogen bonds. 
Briefly, it has been suggested that Hispidin, Lepidine E, and folic acid prevent the spreading of viral infection by stopping the COVID-19's lifecycle through inhibiting the activity of 3CL enzyme strongly (164). In a study conducted by Andre Fischer et al. in 2020, a total of 606 million compounds were extracted from the ZINC database, and all compounds in three-dimensional form were screened with respect to their shape similarity versus a pre-selected set of known and cocrystallized inhibitors of SARS-CoV-1 and SARS-CoV-2. Then, the high number of initial hits were refined to 14240 compounds by selecting the best hits regarding shape overlap. The remaining compounds were docked into the active site of five representative structures of the protease using the smina docking protocol. Among these compounds, 5490 potential hits were selected based on a score below the defined threshold of-7.0 $\mathrm{kcal} / \mathrm{mol}$. Glide SP was used as the second docking protocol to evaluate the interaction of the remaining 5490 compounds with the binding site of the protease, in order to increase confidence in ligand ranking based on docking scores. Then, compounds were clustered according to the Tanimoto coefficient. The two compounds with the best Glide score were selected and evaluated regarding their pharmacokinetic properties. This selection process resulted in 144 compounds used for final MD simulations and freeenergy calculations. Compounds with a predicted binding free energy better than the cocrystallized ligand were finally selected and 29 compounds were characterized by their potential toxicity, assessed by the VirtualToxLab. The final 29 compounds included 13 compounds with a toxic potential above 0.5 that were discarded from the final set. The final compound selection was measuring ligand efficiency. Concisely, a virtual screening workflow consisting of seven individual steps have been applied to ultimately determine 12 potential binders. In order to provide immediate advice to ongoing clinical treatment options, existing protease inhibitors were evaluated in this study and an additional list of nine compounds including apixaban and nelfinavir as top hits have been reported. Furthermore, two natural compounds with the lowest predicted binding free energy namely taxifolin and rhamnetin have been evaluated as potential inhibitors of Mpro. The Persian walnut (Juglans regia), Agrimonia pilosa, and Japanese cypress (Chamaecyparis obtusa) are natural sources for the extraction of taxofolin (165). In a pre-printed study conducted in 2020, GeneCard17 was used to select mutated genes of SARS-CoV and MERS$\mathrm{CoV}$, Tumor Necrosis Factor (TNF), and AngiotensinConverting Enzyme 2 (ACE2). Then, around 150 drug compounds that were effective against SARS-CoV and MERS-CoV were selected and then screened through ZINC15 Database, and the Lipinski rule of five was used to optimize active drug development structure based on the pharmacokinetics of drugs in human beings' body (166). Thence force, clustering-based drug-drug interaction (DDI) networks, and drug repositioning approach were used based on modularity in order to prevent receptor binding capacity and membrane fusion of 2019-nCov. GEPHI was used to make the intensely interacted cluster. Then, promising drug candidates were filtered by the toxicity indicator via ProTox web server (167). For molecular docking, the PDB RCSB server was utilized to recover post-fusion core of 2019-nCoV S2 subunit protein; afterward, complexes of protein-ligand were predicted through submitting ligands (drug compounds) and prepared protein Pdb files. Analysis of molecular docking showed that ZINC000029038525 and ZINC000029129064 drug compounds have the lowest binding energies which means significant potential binding with active sites of post fusion core of 2019-nCov 'S2'. As S2 subunit of 2019-nCov is a main element in fusion of 2019-nCov with host cell membrane which leads to inoculation of its DNA in to the host cell, these compounds may be able to prevent membrane fusion and receptor binding capacity of 2019-nCov and it makes them strong effective therapeutic candidates against 2019-nCov infections (168).

In conclusion, Since the first detection of the $2019-\mathrm{nCoV}$ in Wuhan, China, the COVID-19 is spreading worldwide. There is an urgent need to find efficient therapeutic strategies against it. The development of new drugs has shown some progress but no specific treatment against this new virus is still available. Therefore, the current insightful review evaluates the proposed in vitro, in vivo and in silico therapeutic protocols and earlier records that affords comprehensive information about the contemporary situation of COVID-19 and depicts a picture of the current status of the art with regards to epidemiology, virology, clinical features, diagnosis, and available treatments.

\section{Conflicts of Interest}

The authors declare no conflicts of interest.

\section{Funding}

This research received no outside funding.

\section{References}

1. Marra MA, Jones SJM, Astell CR, Holt RA, Brooks-Wilson A, Butterfield YSN, et al. The genome sequence of the SARSassociated coronavirus. Science (80- ). 2003;300(5624):1399404.

2. Al-Tawfiq JA, Zumla A, Memish ZA. Travel implications of emerging coronaviruses: SARS and MERS-CoV. Travel Med Infect Dis. 2014;12(5):422-8.

3. Chan JF-W, To KK-W, Tse H, Jin D-Y, Yuen K-Y. Interspecies transmission and emergence of novel viruses: lessons from bats and birds. Trends Microbiol. 2013;21(10):544-55.

4. Cascella M, Rajnik M, Aleem A, Dulebohn SC, Di Napoli R. Features, Evaluation, and Treatment of Coronavirus (COVID19). 2021 Apr 20. In: StatPearls [Internet]. Treasure Island (FL): StatPearls Publishing; 2021 Jan-. PMID: 32150360.

5. Wu A, Peng Y, Huang B, Ding X, Wang X, Niu P, et al. Genome Composition and Divergence of the Novel Coronavirus (2019-nCoV) Originating in China. Cell Host Microbe. 2020 Mar 11;27(3):325-328. doi: 
10.1016/j.chom.2020.02.001. Epub 2020 Feb 7. PMID: 32035028 ; PMCID: PMC7154514.

6. Lu R, Zhao X, Li J, Niu P, Yang B, Wu H, et al. Genomic characterisation and epidemiology of 2019 novel coronavirus: implications for virus origins and receptor binding. Lancet. 2020;395(10224):565-74.

7. Wu D, Zou S, Bai T, Li J, Zhao X, Yang L, et al. Poultry farms as a source of avian influenza A (H7N9) virus reassortment and human infection. Sci Rep. 2015;5:7630.

8. Song Z, Xu Y, Bao L, Zhang L, Yu P, Qu Y, et al. From SARS to MERS, thrusting coronaviruses into the spotlight. Viruses. 2019;11(1):59.

9. Cui J, Li F, Shi Z-L. Origin and evolution of pathogenic coronaviruses. Nat Rev Microbiol. 2019;17(3):181-92.

10. Weiss SR, Navas-Martin S. Coronavirus pathogenesis and the emerging pathogen severe acute respiratory syndrome coronavirus. Microbiol Mol Biol Rev. 2005;69(4):635-64.

11. Lai MMC. Coronavirus: organization, replication and expression of genome. Annu Rev Microbiol. 1990;44(1):303.

12. Chen Y, Liu Q, Guo D. Emerging coronaviruses: genome structure, replication, and pathogenesis. J Med Virol. 2020;92(4):418-23.

13. Holmes KV. SARS-associated coronavirus. N Engl J Med. 2003;348(20):1948-51.

14. de Groot RJ, Baker SC, Baric RS, Brown CS, Drosten C, Enjuanes L, et al. Commentary: Middle East respiratory syndrome coronavirus (MERS-CoV): announcement of the Coronavirus Study Group. J Virol. 2013;87(14):7790-2.

15. Zhu N, Zhang D, Wang W, Li X, Yang B, Song J, et al. A Novel Coronavirus from Patients with Pneumonia in China, 2019. N Engl J Med. 2020 Feb 20;382(8):727-733. doi: 10.1056/NEJMoa2001017. Epub 2020 Jan 24. PMID: 31978945; PMCID: PMC7092803.

16. Devaux CA, Rolain JM, Colson P, Raoult D. New insights on the antiviral effects of chloroquine against coronavirus: what to expect for COVID-19? Int J Antimicrob Agents. 2020 May;55(5):105938. doi: 10.1016/j.ijantimicag.2020.105938. Epub 2020 Mar 12. PMID: 32171740; PMCID: PMC7118659.

17. Chan JF-W, Yuan S, Kok K-H, To KK-W, Chu H, Yang J, et al. A familial cluster of pneumonia associated with the 2019 novel coronavirus indicating person-to-person transmission: a study of a family cluster. Lancet. 2020;395(10223):514-23.

18. Li Q, Guan X, Wu P, Wang X, Zhou L, Tong Y, et al. Early Transmission Dynamics in Wuhan, China, of Novel Coronavirus-Infected Pneumonia. N Engl J Med. 2020 Mar 26;382(13):1199-1207. doi: 10.1056/NEJMoa2001316. Epub 2020 Jan 29. PMID: 31995857; PMCID: PMC7121484.

19. $\mathrm{Wu} \mathrm{F}, \mathrm{Zhao} \mathrm{S}, \mathrm{Yu}$ B. A new coronavirus associated with human respiratory disease in China. Nature. 2020 Apr;580(7803):E7. doi: 10.1038/s41586-020-2202-3. Erratum for: Nature. 2020 Mar;579(7798):265-269. PMID: 32296181; PMCID: PMC7608129.

20. G Giovanetti M, Benvenuto D, Angeletti S, Ciccozzi M. The first two cases of 2019-nCoV in Italy: Where they come from? J Med Virol. 2020 May;92(5):518-521. doi: 10.1002/jmv.25699. Epub 2020 Feb 12. PMID: 32022275; PMCID: PMC7166327.

21. Paraskevis D, Kostaki EG, Magiorkinis G, Panayiotakopoulos G, Sourvinos G, Tsiodras S. Full-genome evolutionary analysis of the novel corona virus (2019-nCoV) rejects the hypothesis of emergence as a result of a recent recombination event. Infect
Genet Evol. 2020;79:104212.

22. Li X, Zai J, Zhao Q, Nie Q, Li Y, Foley BT, et al. Evolutionary history, potential intermediate animal host, and cross-species analyses of SARS-CoV-2. J Med Virol. 2020;92(6):602-11.

23. Lee J, Chowell G, Jung E. A dynamic compartmental model for the Middle East respiratory syndrome outbreak in the Republic of Korea: a retrospective analysis on control interventions and superspreading events. $\mathrm{J}$ Theor Biol. 2016;408:118-26.

24. Kang CK, Song K-H, Choe PG, Park WB, Bang JH, Kim ES, et al. Clinical and epidemiologic characteristics of spreaders of Middle East respiratory syndrome coronavirus during the 2015 outbreak in Korea. J Korean Med Sci. 2017;32(5):744-9.

25. Yong E. How the pandemic will end. Atl. 2020;

26. $\mathrm{Lu} \mathrm{H}$, Stratton $\mathrm{CW}$, Tang YW. Outbreak of pneumonia of unknown etiology in Wuhan, China: The mystery and the miracle. J Med Virol. 2020 Apr;92(4):401-402. doi: 10.1002/jmv.25678. Epub 2020 Feb 12. PMID: 31950516; PMCID: PMC7166628.

27. Guan W, Ni Z, Hu Y, Liang W, Ou C, He J, et al. Clinical Characteristics of Coronavirus Disease 2019 in China. N Engl J Med. 2020 Apr 30;382(18):1708-1720. doi: 10.1056/NEJMoa2002032. Epub 2020 Feb 28. PMID: 32109013; PMCID: PMC7092819.

28. Zhang W, Du R-H, Li B, Zheng X-S, Yang X-L, Hu B, et al. Molecular and serological investigation of 2019-nCoV infected patients: implication of multiple shedding routes. Emerg Microbes Infect. 2020;9(1):386-9.

29. Huang C, Wang Y, Li X, Ren L, Zhao J, Hu Y, et al. Clinical features of patients infected with 2019 novel coronavirus in Wuhan, China. Lancet. 2020;395(10223):497-506.

30. Committee GO of NH. Office of State Administration of Traditional Chinese Medicine. Notice on the issuance of a programme for the diagnosis and treatment of novel coronavirus (2019-nCoV) infected pneumonia (Trial Version 4). 2020. 2020.

31. Bergquist SH, Partin C, Roberts DL, O'Keefe JB, Tong EJ, Zreloff J, et al. Non-hospitalized Adults with COVID-19 Differ Noticeably from Hospitalized Adults in Their Demographic, Clinical, and Social Characteristics. SN Compr Clin Med. 2020 Aug 14:1-9. doi: 10.1007/s42399-020-00453-3. Epub ahead of print. PMID: 32838186; PMCID: PMC7426161.

32. Kui L, Fang Y-Y, Deng Y, Liu W, Wang M-F, Ma J-P, et al. Clinical characteristics of novel coronavirus cases in tertiary hospitals in Hubei Province. Chin Med J (Engl). 2020 May 5;133(9):1025-1031. doi: 10.1097/CM9.0000000000000744. PMID: 32044814; PMCID: PMC7147277.

33. Chung M, Bernheim A, Mei X, Zhang N, Huang M, Zeng X, et al. CT Imaging Features of 2019 Novel Coronavirus (2019nCoV). Radiology. 2020 Apr;295(1):202-207. doi: 10.1148/radiol.2020200230. Epub 2020 Feb 4. PMID: 32017661 ; PMCID: PMC7194022.

34. Zhou P, Yang X-L, Wang X-G, Hu B, Zhang L, Zhang W, et al. A pneumonia outbreak associated with a new coronavirus of probable bat origin. Nature. 2020;579(7798):270-3.

35. Guo Y-R, Cao Q-D, Hong Z-S, Tan Y-Y, Chen S-D, Jin H-J, et al. The origin, transmission and clinical therapies on coronavirus disease 2019 (COVID-19) outbreak-an update on the status. Mil Med Res. 2020;7(1):1-10.

36. Singer M, Deutschman CS, Seymour CW, Shankar-Hari M, Annane D, Bauer M, et al. The third international consensus 
definitions for sepsis and septic shock (Sepsis-3). Jama. 2016;315(8):801-10.

37. $\mathrm{Xu} X$, Chen $\mathrm{P}$, Wang J, Feng J, Zhou H, Li X, et al. Evolution of the novel coronavirus from the ongoing Wuhan outbreak and modeling of its spike protein for risk of human transmission. Sci China Life Sci. 2020;63(3):457-60.

38. Li F, Li W, Farzan M, Harrison SC. Structure of SARS coronavirus spike receptor-binding domain complexed with receptor. Science (80- ). 2005;309(5742):1864-8.

39. Zhang $\mathrm{H}$, Penninger JM, Li $\mathrm{Y}$, Zhong N, Slutsky AS. Angiotensin-converting enzyme 2 (ACE2) as a SARS-CoV-2 receptor: molecular mechanisms and potential therapeutic target. Intensive Care Med. 2020 Apr;46(4):586-590. doi: 10.1007/s00134-020-05985-9. Epub 2020 Mar 3. PMID: 32125455; PMCID: PMC7079879.

40. Iwata-Yoshikawa N, Okamura $\mathrm{T}$, Shimizu Y, Hasegawa $\mathrm{H}$, Takeda M, Nagata N. TMPRSS2 contributes to virus spread and immunopathology in the airways of murine models after coronavirus infection. J Virol. 2019;93(6):e01815-18.

41. Tian $\mathrm{S}, \mathrm{Hu} \mathrm{W}$, Niu L, Liu H, Xu H, Xiao SY. Pulmonary Pathology of Early-Phase 2019 Novel Coronavirus (COVID19) Pneumonia in Two Patients With Lung Cancer. J Thorac Oncol. 2020 May;15(5):700-704. doi: 10.1016/j.jtho.2020.02.010. Epub 2020 Feb 28. PMID: 32114094; PMCID: PMC7128866.

42. Mehta P, McAuley DF, Brown M, Sanchez E, Tattersall RS, Manson JJ. COVID-19: consider cytokine storm syndromes and immunosuppression. Lancet. 2020;395(10229):1033-4.

43. Conti P, Ronconi G, Caraffa A, Gallenga CE, Ross R, Frydas I, et al. Induction of pro-inflammatory cytokines (IL-1 and IL-6) and lung inflammation by Coronavirus-19 (COVI-19 or SARSCoV-2): anti-inflammatory strategies. J Biol Regul Homeost Agents. 2020;34(2).

44. Thevarajan I, Nguyen THO, Koutsakos M, Druce J, Caly L, van de Sandt CE, et al. Breadth of concomitant immune responses prior to patient recovery: a case report of non-severe COVID-19. Nat Med. 2020;26(4):453-5.

45. Jia HP, Look DC, Shi L, Hickey M, Pewe L, Netland J, et al. ACE2 receptor expression and severe acute respiratory syndrome coronavirus infection depend on differentiation of human airway epithelia. J Virol. 2005;79(23):14614-21.

46. de Wilde AH, Snijder EJ, Kikkert M, van Hemert MJ. Host Factors in Coronavirus Replication. Curr Top Microbiol Immunol. 2018;419:1-42. doi: 10.1007/82_2017_25. PMID: 28643204; PMCID: PMC7119980.

47. Perrier A, Bonnin A, Desmarets L, Danneels A, Goffard A, Rouillé $\mathrm{Y}$, et al. The C-terminal domain of the MERS coronavirus $\mathrm{M}$ protein contains a trans-Golgi network localization signal. J Biol Chem. 2019;294(39):14406-21.

48. Simmons G, Gosalia DN, Rennekamp AJ, Reeves JD, Diamond SL, Bates P. Inhibitors of cathepsin L prevent severe acute respiratory syndrome coronavirus entry. Proc Natl Acad Sci. 2005;102(33):11876-81.

49. Lei J, Kusov Y, Hilgenfeld R. Nsp3 of coronaviruses: Structures and functions of a large multi-domain protein. Antiviral Res. 2018;149:58-74.

50. McCloskey B, Heymann DL. SARS to novel coronavirus - old lessons and new lessons. Epidemiol Infect. 2020 Feb 5;148:e22. doi: 10.1017/S0950268820000254. PMID: 32019614; PMCID: PMC7026896.

51. Wenzhong L, Hualan L. COVID-19: Attacks the 1-Beta Chain of Hemoglobin and Captures the Porphyrin to Inhibit Human Heme Metabolism. ChemRxiv Prepr. 2020;11938173:v4. . https://doi.org/10.26434/ chemrxiv.11938173.v8

52. Bornstein SR, Dalan R, Hopkins D, Mingrone G, Boehm BO. Endocrine and metabolic link to coronavirus infection. Nat Rev Endocrinol. 2020 Jun;16(6):297-298. doi: 10.1038/s41574020-0353-9. PMID: 32242089; PMCID: PMC7113912.

53. Song $\mathrm{Y}$, Peng $\mathrm{W}$, Tang $\mathrm{D}$, Dai $\mathrm{Y}$. Protease Inhibitor Use in COVID-19. SN Compr Clin Med. 2020 Aug 14:1-8. doi: 10.1007/s42399-020-00448-0. Epub ahead of print. PMID: 32838187 ; PMCID: PMC7426163.

54. Kampf G, Todt D, Pfaender S, Steinmann E. Persistence of coronaviruses on inanimate surfaces and their inactivation with biocidal agents. J Hosp Infect. 2020 Mar;104(3):246-251. doi: 10.1016/j.jhin.2020.01.022. Epub 2020 Feb 6. Erratum in: J Hosp Infect. 2020 Jun 17;: PMID: 32035997; PMCID: PMC7132493.

55. Kashiouris MG, L'Heureux M, Cable CA, Fisher BJ, Leichtle $\mathrm{SW}$. The emerging role of vitamin $\mathrm{C}$ as a treatment for sepsis. Nutrients. 2020;12(2):292.

56. Yang Y, Islam MS, Wang J, Li Y, Chen X. Traditional Chinese medicine in the treatment of patients infected with 2019-new coronavirus (SARS-CoV-2): a review and perspective. Int $\mathrm{J}$ Biol Sci. 2020;16(10):1708.

57. Agostini ML, Andres EL, Sims AC, Graham RL, Sheahan TP, $\mathrm{Lu} \mathrm{X}$, et al. Coronavirus susceptibility to the antiviral remdesivir (GS-5734) is mediated by the viral polymerase and the proofreading exoribonuclease. MBio. 2018;9(2):e00221-18.

58. Wang $\mathrm{M}$, Cao R, Zhang L, Yang $\mathrm{X}$, Liu J, Xu M, et al. Remdesivir and chloroquine effectively inhibit the recently emerged novel coronavirus (2019-nCoV) in vitro. Cell Res. 2020;30(3):269-71.

59. Food and Drug Administration. Remdesivir EUA Letter of Authorization - FDA [Internet]. Vol. 364 KB. 2020. p. 6. Available from: https://www.fda.gov/media/137564/download

60. Savarino A, Di Trani L, Donatelli I, Cauda R, Cassone A. New insights into the antiviral effects of chloroquine. Lancet Infect Dis. 2006;6(2):67-9.

61. Yao X, Ye F, Zhang M, Cui C, Huang B, Niu P, et al. In Vitro Antiviral Activity and Projection of Optimized Dosing Design of Hydroxychloroquine for the Treatment of Severe Acute Respiratory Syndrome Coronavirus 2 (SARS-CoV-2). Clin Infect Dis. 2020 Jul 28;71(15):732-739. doi: 10.1093/cid/ciaa237. PMID: 32150618; PMCID: PMC7108130.

62. Fox R. Anti-malarial drugs: possible mechanisms of action in autoimmune disease and prospects for drug development. Lupus. 1996;5(1_suppl):4-10.

63. Ben-Zvi I, Kivity S, Langevitz P, Shoenfeld Y. Hydroxychloroquine: from malaria to autoimmunity. Clin Rev Allergy Immunol. 2012;42(2):145-53.

64. Cortegiani A, Ingoglia G, Ippolito M, Giarratano A, Einav S. A systematic review on the efficacy and safety of chloroquine for the treatment of COVID-19. J Crit Care. 2020 Jun;57:279-283. doi: 10.1016/j.jcrc.2020.03.005. Epub 2020 Mar 10. PMID: 32173110; PMCID: PMC7270792.

65. Gautret $\mathrm{P}$, Lagier J-C, Parola $\mathrm{P}$, Meddeb L, Mailhe M, Doudier $\mathrm{B}$, et al. Hydroxychloroquine and azithromycin as a treatment of COVID-19: results of an open-label non-randomized clinical trial. Int J Antimicrob Agents. 2020 Jul;56(1):105949. doi: 10.1016/j.ijantimicag.2020.105949. Epub 2020 Mar 20. PMID: 32205204; PMCID: PMC7102549. 
66. Su B, Wang Y, Zhou R, Jiang T, Zhang H, Li Z, et al. Efficacy and Tolerability of Lopinavir/Ritonavir- and Efavirenz-Based Initial Antiretroviral Therapy in HIV-1-Infected Patients in a Tertiary Care Hospital in Beijing, China. Front Pharmacol. 2019 Dec 12;10:1472. doi: 10.3389/fphar.2019.01472. PMID: 31920659; PMCID: PMC6920196.

67. Arabi YM, Alothman A, Balkhy HH, Al-Dawood A, AlJohani S, Al Harbi S, et al. Treatment of Middle East Respiratory Syndrome with a combination of lopinavir-ritonavir and interferon- $\beta 1 \mathrm{~b}$ (MIRACLE trial): study protocol for a randomized controlled trial. Trials. 2018;19(1):81.

68. Liu X, Wang X-J. Potential inhibitors for 2019-nCoV coronavirus $\mathrm{M}$ protease from clinically approved medicines. bioRxiv. 2020;

69. Delang L, Abdelnabi R, Neyts J. Favipiravir as a potential countermeasure against neglected and emerging RNA viruses. Antiviral Res. 2018;153:85-94.

70. Dong $\mathrm{L}, \mathrm{Hu} \mathrm{S}, \mathrm{Gao} \mathrm{J}$. Discovering drugs to treat coronavirus disease 2019 (COVID-19). Drug Discov Ther. 2020;14(1):5860 .

71. Crumpacker CS. Ganciclovir. N Engl J Med. 1996;335(10):721-9.

72. Shiraki K. Antiviral Drugs Against Alphaherpesvirus. Adv Exp Med Biol. 2018;1045:103-122. doi: 10.1007/978-981-10-72307 6. PMID: 29896665.

73. Blaising J, Polyak SJ, Pécheur E-I. Arbidol as a broadspectrum antiviral: an update. Antiviral Res. 2014;107:84-94.

74. Chu CM, Cheng VCC, Hung IFN, Wong MML, Chan KH, Chan KS, et al. Role of lopinavir/ritonavir in the treatment of SARS: initial virological and clinical findings. Thorax. 2004;59(3):252-6.

75. Rossignol J-F. Nitazoxanide: a first-in-class broad-spectrum antiviral agent. Antiviral Res. 2014;110:94-103.

76. Hsieh H-P, Hsu JT-A. Strategies of development of antiviral agents directed against influenza virus replication. Curr Pharm Des. 2007;13(34):3531-42.

77. Nishimura H, Yamaya M. A synthetic serine protease inhibitor, Nafamostat Mesilate, is a drug potentially applicable to the treatment of Ebola virus disease. Tohoku J Exp Med. 2015;237(1):45-50.

78. Uyeki TM. Oseltamivir Treatment of Influenza in Children. Clin Infect Dis. 2018 May 2;66(10):1501-1503. doi: 10.1093/cid/cix1150. PMID: 29315362; PMCID: PMC6669028.

79. Rosa SGV, Santos WC. Clinical trials on drug repositioning for COVID-19 treatment. Rev Panam Salud Publica. 2020 Mar 20;44:e40. doi: 10.26633/RPSP.2020.40. PMID: 32256547; PMCID: PMC7105280.

80. Wang Y, Fei D, Vanderlaan M, Song A. Biological activity of bevacizumab, a humanized anti-VEGF antibody in vitro. Angiogenesis. 2004;7(4):335-45.

81. Santos JR, Curran A, Navarro-Mercade J, Ampuero MF, Pelaez P, Pérez-Alvarez N, et al. Simplification of antiretroviral treatment from darunavir/ritonavir monotherapy to darunavir/cobicistat monotherapy: effectiveness and safety in routine clinical practice. AIDS Res Hum Retroviruses. 2019;35(6):513-8.

82. Mathias AA, German P, Murray BP, Wei L, Jain A, West S, et al. Pharmacokinetics and pharmacodynamics of GS-9350: a novel pharmacokinetic enhancer without anti-HIV activity. Clin Pharmacol Ther. 2010;87(3):322-9.
83. Luo $\mathrm{Y}$, Wang $\mathrm{C}-\mathrm{Z}$, Hesse-Fong J, Lin J-G, Yuan C-S. Application of Chinese medicine in acute and critical medical conditions. Am J Chin Med. 2019;47(06):1223-35.

84. Hoffmann $M$, Kleine-Weber $H$, Krüger $N$, Mueller MA, Drosten C, Pöhlmann S. The novel coronavirus 2019 (2019$\mathrm{nCoV}$ ) uses the SARS-coronavirus receptor ACE2 and the cellular protease TMPRSS2 for entry into target cells. bioRxiv 2020.01.31.929042; https://doi.org/10.1101/2020.01.31.929042

doi:

85. Newfield C. New Medical Indications for Thalidomide and its Derivatives. Sci J Lander Coll Arts Sci. 2018;12(1):3.

86. Zhang W, Zhao Y, Zhang F, Wang Q, Li T, Liu Z, et al. The use of anti-inflammatory drugs in the treatment of people with severe coronavirus disease 2019 (COVID-19): The Perspectives of clinical immunologists from China. Clin Immunol. $2020 \quad$ May;214:108393. doi: 10.1016/j.clim.2020.108393. Epub 2020 Mar 25. PMID: 32222466 ; PMCID: PMC7102614.

87. Markham A, Keam SJ. Danoprevir: First Global Approval. Drugs. 2018;78(12):1271-6.

88. Richardson $\mathrm{P}$, Griffin I, Tucker C, Smith D, Oechsle O, Phelan A, et al. Baricitinib as potential treatment for 2019-nCoV acute respiratory disease. Lancet (London, England). 2020;395(10223):e30.

89. Fang L, Karakiulakis G, Roth M. Are patients with hypertension and diabetes mellitus at increased risk for COVID-19 infection? Lancet Respir Med. 2020 Apr;8(4):e21. doi: 10.1016/S2213-2600(20)30116-8. Epub 2020 Mar 11. Erratum in: Lancet Respir Med. 2020 Jun;8(6):e54. PMID: 32171062; PMCID: PMC7118626.

90. Sorbera LA, Graul AI, Dulsat C. Taking aim at a fast-moving target: targets to watch for SARS-CoV-2 and COVID-19. Drugs Future. 2020;45(4).

91. Campbell CM, Kahwash R. Will Complement Inhibition Be the New Target in Treating COVID-19-Related Systemic Thrombosis? Circulation. 2020 Jun 2;141(22):1739-1741. doi: 10.1161/CIRCULATIONAHA.120.047419. Epub 2020 Apr 9. PMID: 32271624.

92. O'Keefe BR, Giomarelli B, Barnard DL, Shenoy SR, Chan PKS, McMahon JB, et al. Broad-spectrum in vitro activity and in vivo efficacy of the antiviral protein griffithsin against emerging viruses of the family Coronaviridae. J Virol. 2010;84(5):2511-21.

93. Xu Z, Peng C, Shi Y, Zhu Z, Mu K, Wang X, et al. Nelfinavir was predicted to be a potential inhibitor of 2019-nCov main protease by an integrative approach combining homology modelling, molecular docking and binding free energy calculation. bioRxiv 2020.01.27.921627; doi: https://doi.org/10.1101/2020.01.27.921627

94. Zhang J, Ma X, Yu F, Liu J, Zou F, Pan T, et al. Teicoplanin potently blocks the cell entry of 2019-nCoV. bioRxiv 2020.02.05.935387; https://doi.org/10.1101/2020.02.05.935387

95. Li G, De Clercq E. Therapeutic options for the 2019 novel coronavirus (2019-nCoV). Nat Rev Drug Discov. 2020 Mar;19(3):149-150. doi: 10.1038/d41573-020-00016-0. PMID: 32127666 .

96. Fintelman-Rodrigues N, Sacramento CQ, Lima CR, da Silva FS, Ferreira A, Mattos M, et al. Atazanavir inhibits SARSCoV-2 replication and pro-inflammatory cytokine production. bioRxiv. 20 bioRxiv 2020.04.04.020925; doi: https://doi.org/10.1101/2020.04.04.020925 20; 
97. Tran DH, Sugamata R, Hirose T, Suzuki S, Noguchi Y, Sugawara A, et al. Azithromycin, a 15-membered macrolide antibiotic, inhibits influenza A (H1N1) pdm09 virus infection by interfering with virus internalization process. J Antibiot (Tokyo). 2019;72(10):759-68.

98. Deftereos SG, Siasos G, Giannopoulos G, Vrachatis DA, Angelidis C, Giotaki SG, et al. The Greek study in the effects of colchicine in COvid-19 complications prevention (GRECCO-19 study): Rationale and study design. Hellenic J Cardiol. $2020 \quad$ Jan-Feb;61(1):42-45. doi: 10.1016/j.hjc.2020.03.002. Epub 2020 Apr 3. PMID: 32251729; PMCID: PMC7194546.

99. Clinical course and risk factors for mortality of adult inpatients with COVID-19 in Wuhan, China: a retrospective cohort study. Lancet. 2020 Mar 28;395(10229):1054-1062. doi: 10.1016/S0140-6736(20)30566-3. Epub 2020 Mar 11. Erratum in: Lancet. 2020 Mar 28;395(10229):1038. Erratum in: Lancet. 2020 Mar 28;395(10229):1038. PMID: 32171076; PMCID: PMC7270627.

100. Xu X, Han M, Li T, Sun W, Wang D, Fu B, et al. Effective treatment of severe COVID-19 patients with tocilizumab. ChinaXiv. 2020;202003(00026):v1.

101. Miao $\mathrm{M}$, De Clercq $\mathrm{E}$, Li G. Clinical significance of chemokine receptor antagonists. Expert Opin Drug Metab Toxicol. 2020 Jan;16(1):11-30. doi: 10.1080/17425255.2020.1711884. Epub 2020 Jan 17. PMID: 31903790 .

102. Cherin P, Marie I, Michallet M, Pelus E, Dantal J, Crave J-C, et al. Management of adverse events in the treatment of patients with immunoglobulin therapy: a review of evidence. Autoimmun Rev. 2016;15(1):71-81.

103. Srinivasan S, Ghosh M, Maity S, Varadarajan R. Broadly neutralizing antibodies for therapy of viral infections. Antib Technol J. 2016;6:1.

104. Chen L, Xiong J, Bao L, Shi Y. Convalescent plasma as a potential therapy for COVID-19. Lancet Infect Dis. 2020;20(4):398-400.

105. Shen $C$, Wang $Z$, Zhao F, Yang Y, Li J, Yuan J, et al. Treatment of 5 critically ill patients with COVID-19 with convalescent plasma. Jama. 2020;323(16):1582-9.

106. Rajendran $K$, Narayanasamy $K$, Rangarajan J, Rathinam J, Natarajan M, Ramachandran A. A. Convalescent plasma transfusion for the treatment of COVID-19: Systematic review. J Med Virol. 2020 Sep;92(9):1475-1483. doi: 10.1002/jmv.25961. Epub 2020 May 12. PMID: 32356910; PMCID: PMC7267113.

107. Nile SH, Nile A, Qiu J, Li L, Jia X, Kai G. COVID-19: Pathogenesis, cytokine storm and therapeutic potential of interferons. Cytokine Growth Factor Rev. 2020 Jun;53:66-70. doi: 10.1016/j.cytogfr.2020.05.002. Epub 2020 May 7. PMID: 32418715; PMCID: PMC7204669.

108. Negishi H, Taniguchi $T$, Yanai $H$. The interferon (IFN) class of cytokines and the IFN regulatory factor (IRF) transcription factor family. Cold Spring Harb Perspect Biol. 2018;10(11):a028423.

109. Guida G, Riccio AM. Immune induction of airway remodeling. Semin Immunol. 2019 Dec;46:101346. doi: 10.1016/j.smim.2019.101346. Epub 2019 Nov 14. PMID: 31734128 .

110. Stockman LJ, Bellamy R, Garner P. SARS: systematic review of treatment effects. PLoS Med. 2006;3(9).

111. Francis MJ. Recent advances in vaccine technologies. Vet Clin
North Am Small Anim Pract. 2018;48(2):231.

112. Pang J, Wang MX, Ang IYH, Tan SHX, Lewis RF, Chen JI-P, et al. Potential rapid diagnostics, vaccine and therapeutics for 2019 novel coronavirus (2019-nCoV): a systematic review. J Clin Med. 2020;9(3):623.

113. Folegatti PM, Bittaye M, Flaxman A, Lopez FR, Bellamy D, Kupke A, et al. Safety and immunogenicity of a candidate Middle East respiratory syndrome coronavirus viral-vectored vaccine: a dose-escalation, open-label, non-randomised, uncontrolled, phase 1 trial. Lancet Infect Dis. 2020 Jul;20(7):816-826. doi: 10.1016/S1473-3099(20)30160-2. Epub 2020 Apr 21. Erratum in: Lancet Infect Dis. 2020 May 12;: Erratum in: Lancet Infect Dis. 2020 Jun 8;: PMID: 32325038; PMCID: PMC7172901.

114. Zhu F-C, Guan X-H, Li Y-H, Huang J-Y, Jiang T, Hou L-H, et al. Immunogenicity and safety of a recombinant adenovirus type-5-vectored COVID-19 vaccine in healthy adults aged 18 years or older: a randomised, double-blind, placebo-controlled, phase 2 trial. Lancet. 2020 Aug 15;396(10249):479-488. doi: 10.1016/S0140-6736(20)31605-6. Epub 2020 Jul 20. PMID: 32702299; PMCID: PMC7836858.

115. Chen G-Y, Tang J, Zheng P, Liu Y. CD24 and Siglec-10 selectively repress tissue damage-induced immune responses. Science (80- ). 2009;323(5922):1722-5.

116. Toubai $T$, Rossi $C$, Oravecz-Wilson $K$, Zajac C, Liu C, Braun $\mathrm{T}$, et al. Siglec-G represses DAMP-mediated effects on T cells. JCI insight. 2017;2(14).

117. Lisi L, Lacal PM, Barbaccia ML, Graziani G. Approaching Coronavirus Disease 2019: mechanisms of action of repurposed drugs with potential activity against SARS-CoV-2. Biochem Pharmacol. 2020;114169.

118. Galipeau J, Sensébé L. Mesenchymal stromal cells: clinical challenges and therapeutic opportunities. Cell Stem Cell. 2018;22(6):824-33.

119. Gupta N, Krasnodembskaya A, Kapetanaki M, Mouded M, Tan $\mathrm{X}$, Serikov V, et al. Mesenchymal stem cells enhance survival and bacterial clearance in murine Escherichia coli pneumonia. Thorax. 2012;67(6):533-9.

120. Leng $Z$, Zhu R, Hou $W$, Feng $Y$, Yang $Y$, Han $Q$, et al. Transplantation of ACE2-mesenchymal stem cells improves the outcome of patients with COVID-19 pneumonia. Aging Dis. 2020;11(2):216.

121. Bruno S, Bussolati B, Grange $C$, Collino F, di Cantogno LV, Herrera $\mathrm{MB}$, et al. Isolation and characterization of resident mesenchymal stem cells in human glomeruli. Stem Cells Dev. 2009;18(6):867-80.

122. Luo H, Tang Q, Shang $Y$, Liang $S$, Yang M, Robinson N, et al. Can Chinese medicine be used for prevention of corona virus disease 2019 (COVID-19)? A review of historical classics, research evidence and current prevention programs. Chin J Integr Med. 2020;1-8.

123. Xu X, Zhang Y, Li X, Li XX. Analysis on prevention plan of corona virus disease-19 (COVID-19) by traditional Chinese medicine in various regions. Chin Tradit Herb Drugs. 2020;51:1-8

124. Ren J, Zhang A-H, Wang X-J. Traditional Chinese medicine for COVID-19 treatment. Pharmacol Res. 2020;155:104743.

125. Verma S. Preprints 2020, 2020030353 (doi: 10.20944/preprints202003.0353.v1).

126. Liu $X$, Zhang M, He L, Li Y. Chinese herbs combined with Western medicine for severe acute respiratory syndrome 
(SARS). Cochrane Database Syst Rev. 2012;(10).

127. Guo L, Ren L, Yang S, Xiao M, Chang D, Yang F, et al. Profiling early humoral response to diagnose novel coronavirus disease (COVID-19). Clin Infect Dis. 2020 Jul 28;71(15):778785. doi: 10.1093/cid/ciaa310. PMID: 32198501; PMCID: PMC7184472.

128. Zhao J, Yuan Q, Wang $\mathrm{H}$, Liu W, Liao $\mathrm{X}, \mathrm{Su} \mathrm{Y}$, et al. Antibody responses to SARS-CoV-2 in patients of novel coronavirus disease 2019. Clin Infect Dis. 2020 Nov 19;71(16):2027-2034. doi: 10.1093/cid/ciaa344. PMID: 32221519; PMCID: PMC7184337.

129. Li Z, Yi Y, Luo X, Xiong N, Liu Y, Li S, et al. Development and clinical application of a rapid IgM-IgG combined antibody test for SARS-CoV-2 infection diagnosis. Med Virol. 2020 Sep;92(9):1518-1524. doi: 10.1002/jmv.25727. Epub 2020 Apr 13. PMID: 32104917; PMCID: PMC7228300.

130. Wu Z, McGoogan JM. Characteristics of and important lessons from the coronavirus disease 2019 (COVID-19) outbreak in China: summary of a report of 72314 cases from the Chinese Center for Disease Control and Prevention. JAMA. 2020 Apr 7;323(13):1239-1242. doi: 10.1001/jama.2020.2648. PMID: 32091533 .

131. Organization WH. Coronavirus disease 2019 (COVID-19): situation report, 72. 2020;

132. Liu J, Cao R, Xu M, Wang $\mathrm{X}$, Zhang $\mathrm{H}$, Hu $\mathrm{H}$, et al. Hydroxychloroquine, a less toxic derivative of chloroquine, is effective in inhibiting SARS-CoV-2 infection in vitro. Cell Discov. 2020;6(1):1-4.

133. Cao B, Wang Y, Wen D, Liu W, Wang J, Fan G, et al. A trial of lopinavir-ritonavir in adults hospitalized with severe Covid19. N Engl J Med. 2020 May 7;382(19):1787-1799. doi: 10.1056/NEJMoa2001282. Epub 2020 Mar 18. PMID: 32187464; PMCID: PMC7121492.

134. Cai Q, Yang M, Liu D, Chen J, Shu D, Xia J, et al. Experimental treatment with favipiravir for COVID-19: an open-label control study. Engineering (Beijing). 2020 Oct;6(10):1192-1198. doi: 10.1016/j.eng.2020.03.007. Epub 2020 Mar 18. PMID: 32346491; PMCID: PMC7185795.

135. Gao J, Tian Z, Yang X. Breakthrough: Chloroquine phosphate has shown apparent efficacy in treatment of COVID-19 associated pneumonia in clinical studies. Biosci Trends. 2020 Mar 16;14(1):72-73. doi: 10.5582/bst.2020.01047. Epub 2020 Feb 19. PMID: 32074550.

136. Abdulamir AS, Hafidh RR. The Possible Immunological Pathways for the Variable Immunopathogenesis of COVID--19 Infections among Healthy Adults, Elderly and Children. Electron J Gen Med. 2020;17(4).

137. Nicastri E, Petrosillo N, Bartoli TA, Lepore L, Mondi A, Palmieri F, et al. National Institute for the Infectious Diseases "L. Spallanzani", IRCCS. Recommendations for COVID-19 clinical management. Infect Dis Rep. 2020;12(1).

138. Sheahan TP, Sims AC, Leist SR, Schäfer A, Won J, Brown AJ, et al. Comparative therapeutic efficacy of remdesivir and combination lopinavir, ritonavir, and interferon beta against MERS-CoV. Nat Commun. 2020;11(1):1-14.

139. Organization WH. SARS: Clinical Trials on Treatment Using a Combination of Traditional Chinese Medicine and Western Medicine. WHO, Geneva, Switz. 2004;1-191.

140. Zhang $\mathrm{D}$, Wu K, Zhang $X$, Deng $S$, Peng B. In silico screening of Chinese herbal medicines with the potential to directly inhibit 2019 novel coronavirus. J Integr Med. 2020;18(2):1528.
141. Kumar D, Chandel V, Raj S, Rathi B. In silico identification of potent FDA approved drugs against Coronavirus COVID-19 main protease: A drug repurposing approach. Chem Biol Lett. 2020;7(3):166-75.

142. Srivastava AK, Kumar A, Tiwari G, Kumar R, Misra N. In Silico Investigations on the Potential Inhibitors for COVID-19 Protease. arXiv Prepr arXiv200310642. 2020;

143. Srivastava AK, Kumar A, Misra N. On the Inhibition of COVID-19 Protease by Indian Herbal Plants: An In Silico Investigation. arXiv Prepr arXiv200403411. 2020;

144. Rao P, Shukla A, Parmar P, Goswami D. Proposing a fungal metabolite-Flaviolin as a potential inhibitor of 3CLpro of novel coronavirus SARS-CoV2 using docking and molecular dynamics. arXiv Prepr arXiv200403806. 2020;

145. Arya R, Das A, Prashar V, Kumar M. Potential inhibitors against papain-like protease of novel coronavirus (SARS-CoV2) from FDA approved drugs. 2020;

146. Orlando SJ, Santiago Y, DeKelver RC, Freyvert Y, Boydston EA, Moehle EA, et al. Zinc-finger nuclease-driven targeted integration into mammalian genomes using donors with limited chromosomal homology. Nucleic Acids Res. 2010;38(15):e152-e152.

147. Gupta MK, Vadde R. A computational structural biology study to understand the impact of mutation on structure-function relationship of inward-rectifier potassium ion channel Kir6. 2 in human. J Biomol Struct Dyn. 2020;1-14.

148. Gupta MK, Vadde R, Gouda G, Donde R, Kumar J, Behera L. Computational approach to understand molecular mechanism involved in BPH resistance in Bt-rice plant. J Mol Graph Model. 2019;88:209-20.

149. Morris GM, Huey R, Lindstrom $W$, Sanner MF, Belew RK, Goodsell DS, et al. AutoDock4 and AutoDockTools4: Automated docking with selective receptor flexibility. J Comput Chem. 2009;30(16):2785-91.

150. Gupta MK, Vemula S, Donde R, Gouda G, Behera L, Vadde R. In-silico approaches to detect inhibitors of the human severe acute respiratory syndrome coronavirus envelope protein ion channel. J Biomol Struct Dyn. 2021 Apr;39(7):2617-2627.

151. Rani R, Singh A, Pareek A, Tomar S. In Silico Guided Drug Repurposing to Combat SARS-CoV-2 by Targeting Mpro, the Key Virus Specific Protease. 2020;

152. Choudhary S, Malik YS, Tomar S, Tomar S. Identification of SARS-CoV-2 cell entry inhibitors by drug repurposing using in silico structure-based virtual screening approach. Chemrxiv. 2020;

153. Sargunam $P$, Sridharan S. In-Silico Drug Designing of Novel Morpholino Based Physcion Drug Candidate and Investigation of Inhibition Effects on Covid-19 RNA Dependent-RNA Polymerase Non Structural Protein 12 (Nsp 12) with ADMET Study. 2020;

154. Sterling T, Irwin JJ. ZINC 15-ligand discovery for everyone. J Chem Inf Model. 2015;55(11):2324-37.

155. Haider Z, Subhani MM, Farooq MA, Ishaq M, Khalid M, Khan RSA, et al. In Silico discovery of novel inhibitors against main protease (Mpro) of SARS-CoV-2 using pharmacophore and molecular docking based virtual screening from ZINC database. Preprints; 2020.

156. Adem S, Eyupoglu V, Sarfraz I, Rasul A, Ali M. Identification of potent COVID-19 main protease (Mpro) inhibitors from natural polyphenols: An in silico strategy unveils a hope against CORONA. 2020; 
157. Hunter S, Apweiler R, Attwood TK, Bairoch A, Bateman A, Binns $\mathrm{D}$, et al. InterPro: the integrative protein signature database. Nucleic Acids Res. 2009;37(suppl_1):D211-5.

158. Dutta K, Shityakov S, Khalifa I, Mal A, Moulik SP, Panda AK, et al. Effects of secondary carbon supplement on biofilmmediated biodegradation of naphthalene by mutated naphthalene 1, 2-dioxygenase encoded by Pseudomonas putida strain KD9. J Hazard Mater. 2018;357:187-97.

159. Dutta K, Shityakov S, Morozova O, Khalifa I, Zhang J, Panda A, et al. Beclabuvir can inhibit the RNA-dependent RNA polymerase of newly emerged novel coronavirus (SARS-CoV2). 2020;

160. Boopathirajan PMK, Vijayakumar K. In-Silico Drug Discovery for Covid19 by Targeting Spike Glycoprotein of SARS COV-2 (Wuhan Corona Virus 2019 Outbreak) Against the Docking Analysis with Structure Predicted Human 'ACE2-FC Region of IGG1'Fusion Protein As a Protein Based Drug. 2020;

161. Xu C, Ke Z, Liu C, Wang Z, Liu D, Zhang L, et al. Systemic in silico screening in drug discovery for Coronavirus Disease (COVID-19) with an online interactive web server. 2020;

162. Lin C-W, Tsai C-H, Tsai F-J, Chen P-J, Lai C-C, Wan L, et al. Characterization of trans-and cis-cleavage activity of the SARS coronavirus 3CLpro protease: basis for the in vitro screening of
anti-SARS drugs. FEBS Lett. 2004;574(1-3):131-7.

163. Balmeh N, Mahmoudi S, Mohammadi N, Karabedianhajiabadi A. Predicted therapeutic targets for COVID-19 disease by inhibiting SARS-CoV-2 and its related receptors. Informatics Med Unlocked. 2020;100407.

164. Serseg T, Benarous K, Yousfi M. Hispidin and Lepidine E: two Natural Compounds and Folic acid as Potential Inhibitors of 2019-novel coronavirus Main Protease (2019-nCoVMpro), molecular docking and SAR study. arXiv Prepr arXiv200408920. 2020;

165. Fischer A, Sellner M, Neranjan S, Lill MA, Smieško M. Potential Inhibitors for Novel Coronavirus Protease Identified by Virtual Screening of 606 Million Compounds. ChemRxiv; 2020.

166. Benet LZ, Hosey CM, Ursu O, Oprea TI. BDDCS, the rule of 5 and drugability. Adv Drug Deliv Rev. 2016;101:89-98.

167. Drwal MN, Banerjee $P$, Dunkel M, Wettig MR, Preissner R. ProTox: a web server for the in silico prediction of rodent oral toxicity. Nucleic Acids Res. 2014;42(W1):W53-8.

168. Abbasi AM, Ayaz Z, Zainab B. In silico elucidation revealed SARS CoV and MERS CoV Drug Compounds could be Potential Therapeutic Candidates against Post Fusion Core (S2) Protein of Novel Coronavirus (2019-nCov). 2020. 